\title{
Mechanisms and adsorption capacities of biochar for the removal of organic and inorganic pollutants from industrial wastewater
}

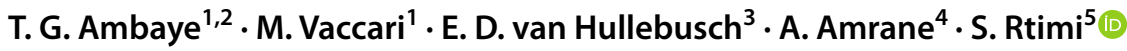

Received: 7 August 2020 / Revised: 1 November 2020 / Accepted: 4 December 2020 / Published online: 26 December 2020

(c) The Author(s) 2020

\begin{abstract}
Currently, due to the rapid growth of urbanization and industrialization in developing countries, a large volume of wastewater is produced from industries that contain chemicals generating high environmental risks affecting human health and the economy if not treated properly. Consequently, the development of a sustainable low-cost wastewater treatment approach has attracted more attention of policymakers and scientists. The present review highlights the recent applications of biochar in removing organic and inorganic pollutants present in industrial effluents. The recent modes of preparation, physicochemical properties and adsorption mechanisms of biochar in removing organic and inorganic industrial pollutants are also reviewed comprehensively. Biochar showed high adsorption of industrial dyes up to 80\%. It also discusses the recent application and mechanism of biochar-supported photocatalytic materials for the degradation of organic contaminants in wastewater. We reviewed also the possible optimizations (such as the pyrolysis temperature, solution $\mathrm{pH}$ ) allowing the increase of the adsorption capabilities of biochar leading to organic contaminants removal. Besides, increasing the pyrolysis temperature of the biochar was seen to lead to an increase in its surface area, while it decreases their amount of oxygen-containing functional groups, consequently leading to a decrease in the adsorption of metal (loid) ions present in the medium. Finally, the review suggests that more research should be carried out to optimize the main parameters involved in biochar production and its regeneration methods. Future efforts should be also carried out towards process engineering to improve its adsorption capacity to increase the economic benefits of its implementation.
\end{abstract}

Keywords Adsorption $\cdot$ Biochar-supported photocatalysts $\cdot$ Inorganic/organic pollutants $\cdot$ Industrial wastewater

\section{Introduction}

Editorial responsibility: Samareh Mirkia.

S. Rtimi

Rtimi.sami@gmail.com

1 Department of Civil, Environmental, Architectural Engineering and Mathematics, University of Brescia, Via Branze 43, 25123 Brescia, Italy

2 Department of Chemistry, Mekelle University, Mekelle, Ethiopia

3 Institut de Physique du Globe de Paris, CNRS, Université de Paris, 75005 Paris, France

4 Ecole Nationale Supérieure de Chimie de Rennes, CNRS, ISCR - UMR6226, University of Rennes, 35000 Rennes, France

5 Ecole Polytechnique Fédérale de Lausanne, 1015 Lausanne, Switzerland
A large amount of wastewater is generated every day from industry (coal and steel industry, non-metallic minerals industry and industries for the surface processing of metals like iron picking and electroplating), which has a huge effect on the environment (Inyang et al. 2012). For this reason, different approaches were applied to treat the industrial wastewater such as advanced oxidation processes (AOPs), reverse osmosis, adsorption, ion exchange, ozonation, precipitation, filtration with coagulation and coagulation process (Park et al. 2011). However, most of these processes require high operational and capital costs. This has been considered as the main obstacle that restricts their application for the abatement/removal of potentially toxic contaminants from polluted waters in developed and developing countries (Giannakis et al. 2017; Villegas- Guzman et al. 2017; Lou et al. 2017; Ambaye et al. 2020).

Biochar, a solid formed from the pyrolysis of biomass at a temperature below $700{ }^{\circ} \mathrm{C}$ under low or in the absence 
of oxygen (Park et al. 2011). The resulting solid is rich in carbon and presents a promising adsorption ability allowing it to remove organic and inorganic contaminants from wastewater. Different waste materials such as straw, faces, sludge have been tested as raw materials for biochar production. Park et al. (2016) proved that different methods such as pyrolysis, hydrothermal carbonization, gasification can be used to produce biochar. One can conclude that the performance of biochar can be affected by (i) the type of the organic materials feedstock, the preparation temperature, modification approaches, among others. Adsorption ability of biochar has been used to manage waste resources (Park et al. 2011), improve soil performance (Liu and Zhang 2009), mitigate the climate change and as renewable biofuels (Kołodyńska et al. 2012).

Many scientists studied the feasibility of biochar prepared from animal manure, plant residues and biosolids for the adsorption of pesticides, pharmaceuticals, hormones and potentially toxic metals (Downie et al. 2009; Joseph et al. 2010; Sun et al.; 2014). They showed that biochar exhibited high efficiency for adsorbing pollutants when compared to activated carbons. Similar results were reported by Özçimen and Karaosmanoğlu (2004) and Hossain et al. (2011) in their studies to remove endocrine disrupting organic compounds from aqueous solutions using biochar prepared from plant biomass. They showed that biochar was able to remove up to $60 \%$ of organic pollutants such as triazine herbicide, $\alpha$-ethinylestradiol, atrazine and bisphenol. They concluded that the absorption ability of biochar to remove pollutants depends upon the preparation feedstock and physiochemical properties of both the biochar and the pollutant. Rice husk was used for the removal of two dyes, namely safranin and methylene blue (Inyang et al. 2014). The adsorption constants showed values of 838 and $312 \mathrm{mg} / \mathrm{g}$ for the two dyes, respectively (Peng et al. 2011).

Sawdust is an agricultural waste material that can be used for the abatement of many dyes, toxic metals and salts from wastewater (Peng et al. 2011). This material contains many compounds (such as cellulose, lignin and hemicellulose) and polyphenolic groups, which play a vital role in binding to organic compounds through various mechanisms including ion exchange, complexation and hydrogen bonding (Thies and Rillig 2009).

The adsorption capacity of orange peel leading to dyes removal from industrial and domestic effluents was extensively studied. The effect of some physicochemical parameters that may affect the absorption performance such as the biochar dosage, the medium acidity, the reaction time and the dyes concentration was studied. Adsorption capacities of 10.72 and $21.05 \mathrm{mg} / \mathrm{g}$ were found for direct red 23 and 80 within the first $15 \mathrm{~min}$ at initial pH 2 (Fuertes et al. 2010). The adsorption capacity of wastes from steel and fertilizer industries for the adsorption of cationic dyes was investigated by Bhatnagar and Jain (2014). Cao and Harris (2010) showed that a very low dyes' adsorption performance was observed for adsorbents prepared from blast furnace sludge, dust and slag. These adsorbents were seen to exhibit a low surface area associated with a poor porosity. However, chemical activation using metal hydroxide reagents (e.g. $\mathrm{KOH}$ ) is the most effective technique for producing high $\left(>1800 \mathrm{~m}^{2} / \mathrm{g}\right)$ surface area of sludge-based adsorbents (Van Zwieten et al. 2010). In recent reports, high efficiency removal of organic pollutants from industrial effluents was observed for biochar; however, the physicochemical properties of biochar may play as limiting factors (Rajapaksha et al. 2015; Peiris et al. 2017; Bielská et al. 2018; Zhang et al. 2018). The disposal of organics and inorganics has become a serious environmental problem, and due to this, there have been stringent regulations for such wastes. Recent research articles showed that technology-based on biochar adsorption is effective in removing heavy metals from wastewater (Inyang et al. 2016; Rizwan et al. 2016; O'Connor et al. 2018; Wei et al. 2018). This material has good adsorption capacity for typical industrial wastewater pollutants such as potentially toxic metals, organic pollutants, phosphorus and nitrogen compounds. Biochar can be used as a release controlling agent in fertilizers thanks to its good adsorption capacity for phosphorus and nitrogen as previously reported (Chen et al. 2011a, b; Yao et al. 2011a, b 2013a, b; Zhang et al. 2013a, b). Because biochar is an environmentally friendly absorbent, the knowledge of its physicochemical properties and a systematic understanding of the adsorption mechanisms is a matter of topical interest.

The adsorption mechanism of biochar to remove organic and inorganic pollutants can be based on electrostatic interaction, ion exchange, pore filling and precipitation. This depends upon the physiochemical characteristics of biochar such as dosage, pyrolysis temperature, $\mathrm{pH}$ of the medium/ effluent (Pellera et al. 2012; Ahmad et al. 2014; Lam et al. 2016; Mubarak et al. 2016; Vithanage et al. 2016; Younis et al. 2016; Rehman et al. 2017; Qayyum et al. 2017). However, due to rapidly growing urbanization and industrialization in developing countries, a large volume of wastewater is generated, which contains chemicals generating high environmental risks which could affect health and socioeconomic activities. Consequently, understanding the application of biochar in wastewater treatment and water purification gets increasing attention even if there is a lack of data dealing with adsorbents for industrial wastewater treatment.

In this paper, we review various forms of biochar sorbing materials for the abatement of pollutants from industrial wastewater. The preparation methods, the biochar characterization, and the different mechanisms involved during pollutant adsorption are discussed, as well as biochar regeneration. Its economic and environmental benefit is also analysed, especially regarding its application on a large scale. The 
review also highlights the future research directions, especially regarding environmental applications of biochar.

\section{Preparation and characteristics of biochar}

\section{Preparation methods of biochar}

Different methods were used for the preparation of biochar. Table 1 summarises some of the preparation methods, preparation conditions and the absorption yield of recently available biochars. Pyrolysis appears to be a major method for the preparation of biochar. Pyrolysis is a decomposition taking place at high temperature in the absence of oxygen. It can be qualified as rapid, slow or "flash" pyrolysis based on the temperature and the reaction time (Downie et al. 2009; Sun et al. 2014). Solid products can be formed due to slower heating rates and lower pyrolysis temperatures. As shown in Table 1, the yield of solid product in the slow pyrolysis is usually $35 \%$, and this reveals that slow pyrolysis can be assumed as the main preparation method of biochar among the three-pyrolysis techniques (Özçimen and Karaosmanoğlu 2004).

Hydrothermal carbonization (HTC) is another major technique for the preparation of biochar. The biochar formed by HTC is more favourable for adsorption of pollutants in aqueous media. Harmful substances are not produced by this process. However, the main limitations associated with this method are related to the high-pressure requirement concomitant to high temperature, and the cost of the reactor as reported by Van Zwieten et al. (2010); however, it may be time-consuming which leads to high cost (Van Zwieten et al. 2010) delaying its practical application. However, recent studies showed that treating sewage sludges and digestate using HTC can overpass its limitation in energy compared to other thermochemical processes. The hydrochar that can be produced from this process was seen to be more stable (Parmar and Ross 2019). For this reason, hydrochar from HTC can improve the biogas production and soil amendment/remediation. There is a need of more research for coupling HTC with anaerobic digestion of process waters in the future for large-scale applications (Parmar and Ross 2019).

In addition to slow pyrolysis and HTC, other methods include rapid pyrolysis, "flash" pyrolysis, gasification and drying. However, such methods have a small yield of solid products and are typically used to produce bio-oil or gaseous materials (Hossain et al. 2011). For example, the gasification method has a yield of about $85 \%$ for the gas product. The content of gaseous products increases by the increase of the temperature.

\section{Characteristics}

The physicochemical properties of biochar are highly influenced by the biomass origin and the preparation conditions. Different biomass presenting different physical, chemical and structural properties can be used to produce biochar. Theoretically, biochar can be prepared from any type of biomass. Various types of feedstock could be used to prepare biochar such as agricultural, aquatic or forest crops (Sun et al. 2014). Biochar can also be produced by transforming/or processing different biowastes such as husks, sawdust, shells and hulls. Other sources of biomass including manures, municipal solid wastes, sewage sludge (Zhang et al. 2017) are shown in Fig. 1.

Many factors can affect the physicochemical properties of biochar. One of the parameters that affect the properties of biochar is the types of the raw material and the size of the substrate. The pyrolysis type (slow, rapid or flash), the temperature, the heating rate, the duration of pyrolysis can also affect drastically the quality of the resulting biochar (Downie et al. 2009; Peng et al. 2011; Thies and Rillig 2009). Biochar presents an abundant number of surface functional groups such as hydroxyl, methyl, carbonyl and carboxyl (Fuertes et al. 2010). Many factors can affect its structure such as the high carbon content, oxygen-containing aromatic functional groups and its high porosity. Its porosity, stable molecular structure and its surface area favour the pollutants' adsorption on its surface (Chen et al. 2014). Some of the abovementioned factors that affect the removal of contaminants from industrial wastewater are discussed below.

\section{Biochar's properties influencing its activity}

The properties of biochar depend upon the pyrolysis temperature, the residence time, the considered feedstock and the thermal conversion technology as mentioned earlier. These factors also affect the removal efficiency of various
Table 1 Conventional techniques used to prepare biochar (Downie et al. 2009; Novak et al. 2009; Sun et al. 2014)

\begin{tabular}{lllllll}
\hline Preparation methods & Temperature $\left({ }^{\circ} \mathrm{C}\right)$ & Heating rate & Reaction time & \multicolumn{3}{l}{ Yield $(\%)$} \\
\cline { 5 - 7 } & & & & Solid & Liquid & Gas \\
\hline Slow pyrolysis & $<700$ & Slow & Hours & 35 & 30 & 35 \\
Fast pyrolysis & $<1000$ & Fast & Seconds & 10 & 70 & 20 \\
Flash pyrolysis & $775-1025$ & Faster & SECONDS & $10-15$ & $70-80$ & $5-20$ \\
Hydro-carbonization & $<350$ & Slow & Minutes-hours & $50-80$ & - & - \\
Gasification & $700-1500$ & Faster & Seconds-minutes & 10 & 5 & 85 \\
\hline
\end{tabular}


Fig. 1 Classification of biochar ( Adapted from Dai et al. 2019)

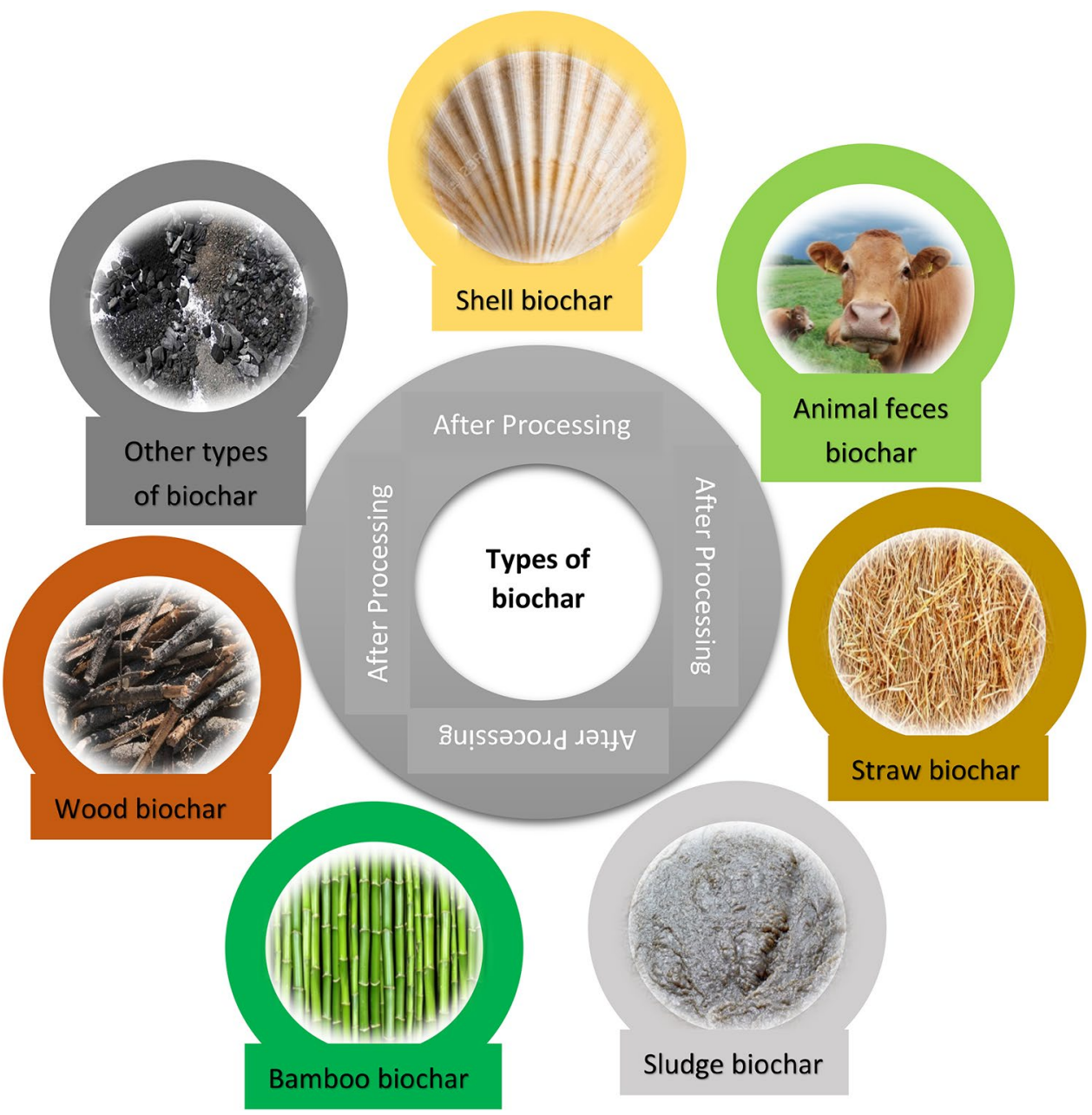

contaminants (Chen et al. 2012). The adsorption of organic contaminants using biochar prepared from pine needles at temperatures going from 100 to $700{ }^{\circ} \mathrm{C}$ was studied by Chen and Chen (2009). They showed that the pore size and the specific surface areas of biochar increase proportionally with the pyrolysis temperature. Chen et al. (2012) as well as Ahmad et al. (2012) proposed that the presence of carbonized matter, surface area, pores and hydrophobicity of biochar increased when the temperature was increased, which in turn led to increase the adsorption yield of naphthalene. Also, the existence of more carbonized matter in biochar favours the removal of organic contaminants having a functional group of oxygen and hydrogen (Ahmad et al. 2012). Moreover, the adsorption of potentially toxic metals on biochar can also be enhanced by optimizing the pyrolysis temperature. Kim et al. (2012) studied the effects of pyrolysis temperature greater than $500{ }^{\circ} \mathrm{C}$ on the biochar's $\mathrm{pH}$ and surface area. They applied their biochar to the adsorption of $\mathrm{Cd}$ in aqueous media. In contrast, O'Connor et al. (2018) showed that the increase of the pyrolysis temperature led to the decrease in the removal of $\mathrm{Cr}(\mathrm{VI})$ in aqueous medium using biochar produced from coconut.
The latter contributed to the reduction of $\mathrm{Cr}(\mathrm{VI})$ to $\mathrm{Cr}(\mathrm{III})$. This reduction reaction is a serious environmental problem because it is $\mathrm{pH}$ dependent. Ludwig et al. (2007) tried the in situ reduction of $\mathrm{Cr}(\mathrm{VI})$ using ferrous sulphate and sodium dithionite. The reduction kinetics were very slow delaying the practical application of this method.

Thus, it has been reported that increasing the biochar's pyrolysis temperature increases the biochar's surface area, while it decreases the amount of oxygen-containing functional groups on its surface. This latter leads to decrease the adsorption of toxic metals in aqueous media as shown in Fig. 2. These observations were in consistency with those of Inyang et al. (2011). Inyang et al. (2011) observed that the $\mathrm{Pb}$ adsorption on biochar decreased from $21 \mathrm{mg} / \mathrm{L}$ as the pyrolysis temperature increased from 250 to $600{ }^{\circ} \mathrm{C}$ using bagasse biochar. They attributed this to the decrease in the number of oxygen-containing groups at high temperature.

Another parameter affecting the adsorption properties of biochar is the composition of the feedstock (Sun et al. 2014). Indeed, the presence and absence of mineral-like $\mathrm{CO}_{3}{ }^{2-}$, $\mathrm{PO}_{4}{ }^{3-}$ in the feedstock affect the adsorption capacity of the obtained biochar, since these minerals can contribute to 


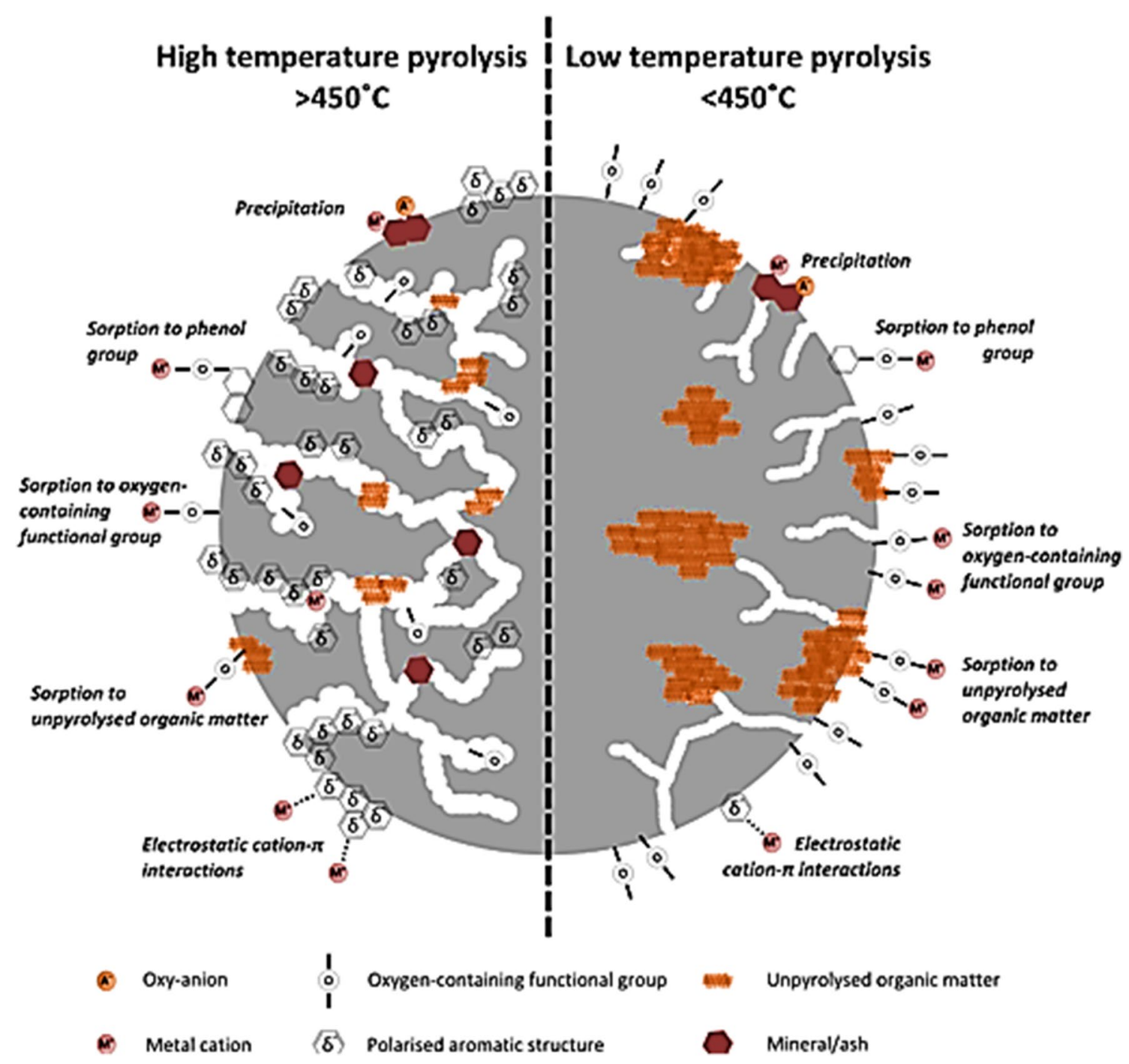

Fig. 2 Mechanisms of metal cations (e.g. $\mathrm{Cd}^{2+}, \mathrm{Cu}^{2+}, \mathrm{Hg}^{2+}, \mathrm{Pb}^{2+}$, $\mathrm{Zn}^{2+}$ ) and oxyanions (e.g. $\mathrm{PO}_{4}{ }^{3-}, \mathrm{AsO}_{4}{ }^{3-}$ ) sorption to biochar prepared by pyrolysis at high temperature $\left(>450{ }^{\circ} \mathrm{C}\right)$ and low temper-

the formation of additional active sorption site, enhancing adsorption of potentially toxic metals from wastewater (Cao et al. 2009). From another side, biochar produced by hydrothermal carbonization (HTC) can produce a higher number of oxygen-containing functional groups (Liu et al. 2010). Similar conclusions were drawn by Kumar et al. (2017) who examined the removal of copper from wastewater using biochar produced by HTC and pyrolysis.

\section{Pollutants' removal mechanisms}

\section{Mechanisms of biochar adsorption}

In adsorption, the adsorbate is associated with the adsorbent's surface until equilibrium is achieved. The steps ature $\left(<450{ }^{\circ} \mathrm{C}\right) \quad$ (Reproduced with permission from Sizmur et al. (2017), Bioresource Technology 246 (2017) 34-47)

involved in the adsorption process include: (a) physical adsorption in which the adsorbate settles on the adsorbent's surface; (b) precipitation and complexation in which the adsorbate deposits on the adsorbent's surface; and (c) pore filling in which the adsorbate is condensed into the pore of the adsorbent (Fagbohungbe et al. 2017). This process occurs in three stages qualifying three zones: the first is the stage in which no adsorption takes place; it is called the clean zone. The second stage is called the mass transfer zone in which the adsorption is in progress. The last step is the stage in which equilibrium is achieved; it is called the exhausted zone (de Ridder et al. 2012). The saturated or exhausted zone increases, while the clean zone decreases during the process. The mass transfer zone is affected if the adsorbate's concentration is increased; otherwise, it is not affected. Such a trend continues until the breakthrough point, 
a point where the adsorbent is saturated (Moreno-Castilla 2004).

\section{Mechanism of the adsorption of toxic metals}

The different mechanisms involved in the toxic metals' removal are surface sorption, ion exchange, electrostatic interaction, precipitation and complexation.

\section{Surface sorption}

It is a physical process that involves the formation of chemical bonds through the diffusion of the metal ions in the pores of the sorbent. The pores' volume and the surface area of the sorbent (biochar) depend upon the carbonization temperature. Kumar et al. (2017) studied the uranium adsorption onto biochar prepared from pinewood at a temperature of 300 and $700{ }^{\circ} \mathrm{C}$. Their results showed that biochar prepared at a high temperature can completely remove uranium than the one prepared at low temperature. They attributed this to the fact that high carbonization enhances the surface area and pores volume of the biochar. Another research reported by Wang et al. (2015) aimed to investigate the adsorption of toxic metals on biochar prepared from hickory wood and treated with $\mathrm{KMnO}_{4}$. Their results showed that the biochar that they prepared exhibited $153.1 \mathrm{mg} \mathrm{g}^{-1}$ adsorption of $\mathrm{Pb}$, $34.2 \mathrm{mg} \mathrm{g}^{-1}$ adsorption of $\mathrm{Cu}$ and $28.1 \mathrm{mg} \mathrm{g}^{-1}$ adsorption of $\mathrm{Cd}$. This difference in the adsorption may be due to the affinity of these metals, presenting different valence towards the biochar.

\section{Electrostatic interaction of metals on biochar}

This mechanism involves the electrostatic interaction between the charged biochar and metals ions to limit the mobilization of potentially toxic metals (Mukherjee et al. 2011). For instance, according to the Qiu et al. (2009) the removal of $\mathrm{Pb}$ from the aqueous solution using biochar prepared from rice and wheat shows high removal of $\mathrm{Pb}$ due to the attraction of the positively charged $\mathrm{Pb}$ and negatively charged of the biochar. In addition to this, they claimed that increasing the pyrolysis temperature greater than $400{ }^{\circ} \mathrm{C}$ can enhance the carbonization of the biochar and leads to an increase in the electrostatic interaction of the biochar to adsorb the pollutant. The same result also reported by Keiluweit et al. (2009), Dong et al. (2011), Agrafioti et al. (2014) and Igalavithana et al. (2017) who reported that electrostatic interaction is the main mechanism involved in the removal potentially toxic metals. However, this immobilization process depends upon the $\mathrm{pH}$ of the solution and point of zero charge of biochar.

\section{Cation/ion exchange capacity}

The exchange of protons and ionized cations with dissolved salts on the biochar's surface is the main principle of this mechanism. Its adsorption capacity to remove heavy metals depends upon the contaminated size and surface functional group of the biochar (Rizwan et al. 2016). Ali et al. (2017) reported that the higher the cation exchange capacity of the biochar means the higher adsorption of metals. However, the cation exchange capacity is decreasing with pyrolysis temperatures greater than $350{ }^{\circ} \mathrm{C}$. El-Shafey (2010) investigated the removal of $\mathrm{Hg}^{2+}$ and $\mathrm{Zn}^{2+}$ from polluted water using biochar prepared from rice husk at pyrolysis temperature of $180{ }^{\circ} \mathrm{C}$. They showed that high adsorption of $\mathrm{Hg}$ ions was achieved compared to Zn ions. Trakal et al. (2016) investigated the removal of $\mathrm{Cd}$ and $\mathrm{Pb}$ using biochar prepared from different feedstocks such as wheat straw, graph stalk, grape husk, plum stone and nutshell. The authors showed higher $\mathrm{Pb}$ and $\mathrm{Cd}$ removal efficiency for the feedstocks containing iron oxides. The presence of iron in the biochar feedstock was seen to enhance the cation exchange capacity of the biochar.

\section{Precipitation}

It is one of the main mechanisms that can be used for the removal of inorganic pollutant onto biochar. It involves the formation of mineral precipitates into the solution or onto the surface of the sorbing material, especially for biochar which is produced from the degradation of cellulose and hemicelluloses material through pyrolysis temperature greater than of $300{ }^{\circ} \mathrm{C}$ and having alkaline property (Cao and Harris 2010). Puga et al. (2016) reported that biochar that can be prepared from sugarcane and straw dust can enhance the precipitation of $\mathrm{Cd}$ and $\mathrm{Zn}$. However, they claimed that the efficiency of surface precipitation of the biochar depends on the pyrolysis temperature so that more research needs in the future in the optimization of the pyrolysis temperature.

\section{Complexation}

This mechanism of metal complexation includes the arrangement of multi-atom formation through the interaction of specific metal ligands to form complex. The biochar produced at low temperature can bind with heavy metals thanks to the functional groups which contain oxygen in their structure such as phenolic, lactonic and carboxyl. This oxygen content can increase surface oxidation of the biochar leading to enhance the metal complexation (Mohan and Pittman 2007; Liu and Zhang 2009). It has been shown that biochar prepared from vegetal biomass has high efficiency in the binding of potentially metals such as $\mathrm{Cu}, \mathrm{Cd}, \mathrm{Ni}$ and $\mathrm{Pb}$ to form metal complexes with carboxylic and phenolic functional groups 
when compared with biochar prepared from animals such as dairy manure and poultry litter (Cao et al. 2009; Zhang et al. 2017). They concluded that plant-derived biochar displays high surface complexation and ion exchange capacities. However, more research is needed in order to determine the biochar metal complexes' formation using sophisticated spectroscopic techniques such as X-ray photoelectron spectroscopy (XPS) and Fourier transform infrared spectroscopy (Zhou et al. 2014).

\section{The mechanism involved in the adsorption of organic pollutants}

The different mechanism involved in the organic pollutants' adsorption is pore filling, hydrophobic interaction, partitioning, electrostatic interaction and electron donor-acceptor (EDA) interaction.

\section{Partitioning}

In this process, the adsorbate material diffuses into the pores of the non-carbonized portion of the biochar. This portion can easily interact with the organic adsorbate leading to its sorption. However, the adsorption of organic pollutant compounds depends upon the characteristics of the non-carbonized biochar (crystalline or amorphous carbon) and of carbonized crystalline and graphene fractions of the biochar. Cao et al. (2009) and Zhang et al. (2013a, b) reported that biochar prepared from swine and dairy manure at pyrolysis temperature of 200 and $350{ }^{\circ} \mathrm{C}$ shows high sorbate partitioning of atrazine pollutant using organic carbon (OC) fractions of biochar. Similar results were found by Sun et al. (2011) showing that organic fractions of biochar prepared from wood and grass can enhance the adsorption of norflurazon and fluridone by partitioning. In general, the partitioning mechanism is more visible and highly efficient when the biochar has high volatile matter content and at high concentration of organic contaminants (Keiluweit et al. 2010).

\section{Pore filling}

This is a process in which the organic contaminants are at the surface of biochar having mesopores $(2-50 \mathrm{~nm})$ and micropores $(<2 \mathrm{~nm})$. The pore filing mechanism depends upon nature, type of the biochar, as well as the polarity of the organic contaminant. Kasozi et al. (2010) reported that biochar prepared from gamma grass, oak and loblolly for the sorption of catechol using micropore filling mechanism is more dominant than other adsorption mechanisms. In general, to have high efficiency of this pore filling process, the biochar must contain a small amount of volatile matter and occur at low concentration of organic contaminants.

\section{Electrostatic interaction}

This is the most important mechanism which involves the adsorption of ionizable organic compounds to the positively charged surface of the biochar through electrostatic interaction. Its efficiency to attract or to repel pollutants depends upon the $\mathrm{pH}$ and ionic strength of the aqueous solution (Ahmad et al. 2014; Zheng et al. 2013). Mukherjee et al. (2011) investigated the effect of $\mathrm{pH}$ on the electrostatic interaction between organic contaminants and biochar surface showed positive charge at low $\mathrm{pH}$ value, whereas when the $\mathrm{pH}$ of the aqueous solution is high, it holds a negative charge. This indicates that the net charge of the surface of the biochar is controlled by the $\mathrm{pH}$ of the solution/effluent. The electrostatic interaction of the organic contaminants with biochar is also affected by the ionic strength of the aqueous solution. Inyang et al. (2014) in their experiment related to removal of methylene blue by biochar prepared from bagasse composite with carbon nanotubes (CNT) showed that an increase of the ionic strength of the sorbate solution from 0.01 to $0.1 \mathrm{M} \mathrm{NaCl}$ led to decrease the adsorption of the methylene blue from 4.5 to $3 \mathrm{mg} \mathrm{g}^{-1}$. This was attributed to an increase of the repulsive electrostatic interaction between the sorbent and the sorbate.

\section{Electron donor and acceptor interaction}

The electron donor and acceptor interaction mechanism is mostly applied to the adsorption of aromatic compounds on biochar presenting a graphene-like structure. To have a complete graphitization, a temperature greater than $1100^{\circ} \mathrm{C}$ should be reached during the biochar preparation (Spokas 2010). However, the electron density of the biochar to generate deficient or enriched $\pi$-electron depends upon the pyrolysis temperature of the biochar, that is if the temperature of the biochar is below $500{ }^{\circ} \mathrm{C}$, the system of the biochar $\pi$ aromatic acts as electron acceptor, while if the temperature is above $500^{\circ} \mathrm{C}$, the biochar acts as a donor (Sun et al. 2014; Zheng et al. 2013). Zheng et al. (2013) tried to adsorb sulfamethoxazole using biochar produced from reed and enriched on its surface with $\pi$-electron graphene. A high sorption was observed between the anilineprotonated rings of sulfamethoxazole and the graphene surface of the biochar. Besides they claimed that the $\pi$-electron donor/ acceptor interaction between the electron-withdrawing substituent of chlorine and aromatic carbon on the surface of biochar enhances the adsorption of atrazine compound.

\section{Hydrophobic interaction}

This mechanism can be used for the adsorption of hydrophobic and neutral organic compounds through partitioning and hydrophobic interaction processes. When compared to the partitioning process, the hydrophobic 
interaction mechanism requires less energy. Moreover, the main process for the adsorption of organic pollutants on the surface of the graphene structure is the hydrophobic interaction (Zhu et al. 2005). Similar results were reported by Li et al. (2018) who showed that hydrophobic interaction is the main mechanism involved in the adsorption of ionizable organic pollutants such as benzoic acid, o-chlorobenzene acid and p-chlorobenzene acid. Chen et al. $(2011 \mathrm{a}, \mathrm{b})$ investigated the perfluoro octane sulfonate sorption on biochar produced from maize straw. The removal took place via the hydrophobic interaction due to high hydrophobic nature of the organic pollutant. The adsorption of perfluoro octane sulfonate molecules increased with the increase in the pyrolytic temperature. This was attributed to the decrease in the number of polar groups on the biochar surface caused by the pyrolysis temperature.

The mechanisms of removal of organic and inorganic adsorbates involving the sorption onto biochar are shown in Fig. 3. Metals adsorption on biochar occurs principally through precipitation, ion exchange and electrostatic attraction onto the adsorbent's surface, while the adsorption mechanisms for organic molecules are van der Waals forces, hydrogen bonding and hydrophobic interactions as shown in Fig. 3. Functional groups (hydroxyl, carboxyl, carbonyl, amine) favour the affinity of organic molecules and their adsorption on the biochar's surface. Such adsorption mechanism is an electron donor/acceptor type based on the uneven electrons' distribution between the organic compound and the adsorbent (biochar) functional groups. At this level, it is worth mentioning that the interaction between organic compounds presenting nitro- and chloro-substituent groups and the adsorbent is highly reduced. This leads to an increase in the electrostatic interaction between the organic compound and the biochar (Mu'azu et al. 2017) as it is related to the strong electron acceptor nature of the substituent group in the compound (Atkinson et al. 2010).

\section{Factors affecting contaminants' sorption onto the biochar}

\section{Effect of the $\mathrm{pH}$ of the medium}

It has been reported that the $\mathrm{pH}$ of the aqueous solution affects the sorption of contaminants onto biochar. This is related to the oxygen-containing functional groups, which are $\mathrm{pH}$ dependent. Consequently, the surface charge and ionization
Fig. 3 Different biochar adsorption mechanisms for organic and inorganic contaminants. (Adapted from Ahmad et al. 2014)

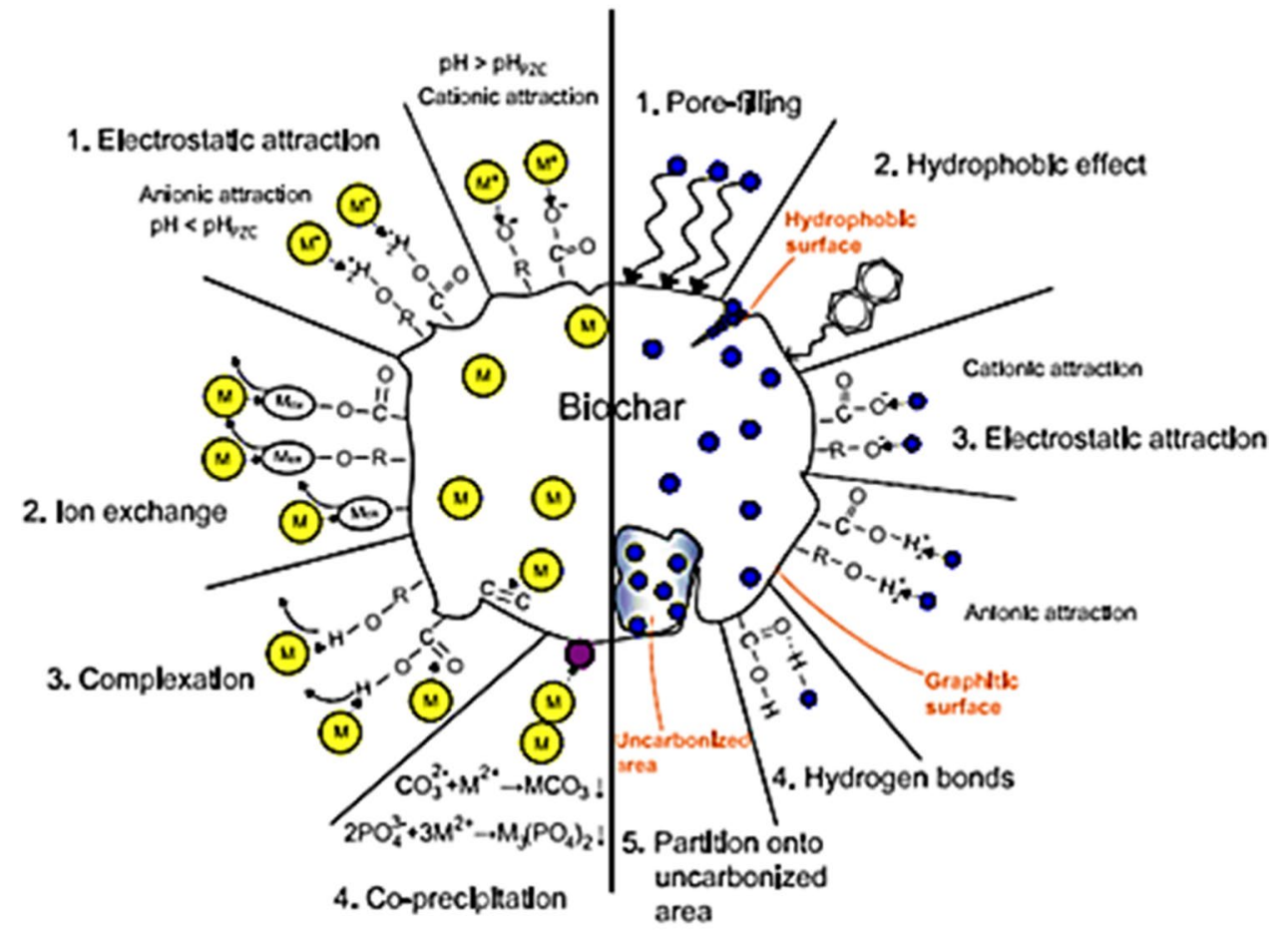

Heavy metals Organic contaminants

\author{
- Organic contamlnants \\ (14) Metalions \\ - Mneral components $\left(\mathrm{CO}_{3}^{*} . \mathrm{PO}_{4}^{*}\right)$ \\ (4) Exchangeable metallons
}


at the surface of the biochar are $\mathrm{pH}$-dependent leading to differentiate adsorption capacity to remove contaminants (Zhang et al. 2013a, b). A deprotonation of the functional groups happens when the $\mathrm{pH}$ of the aqueous solution increases. This leads to the increase of the sorption capacity of biochar towards cationic metals. However, if the $\mathrm{pH}$ decreases, it leads to increase the electrostatic repulsion forces between the protons and metal ions in the aqueous solution. Consequently, a competition between cations for the adsorption sites of the biochar can occur leading to decrease the capacity of the adsorbent material for metal ions (Lu et al. 2012).

In their study to adsorb metals like copper, zinc and lead using biochar produced from hardwood and corn straw, Chen et al. $(2011 \mathrm{a}, \mathrm{b})$ showed that an increase of the $\mathrm{pH}$ from 2.0 to 5.0 led to an increase in the adsorption capacity of the metallic cations. A pH above 5.0 led to decrease the adsorption capacity due to hydroxide complex formation. Similar results were reported by Tong et al. (2011) and Lu et al. (2012). However, Zhang et al. (2013a, b) proposed that decreasing the $\mathrm{pH}$ of the solution leads to an increase in the adsorption capacity of anions such as $\mathrm{Cr}$ (VI) metals ions. This is due to electrostatic interactions between the negative charges of the chromate ion with the positive charge of the biochar functional group at low $\mathrm{pH}$. In contrast, by the removal of $\mathrm{Cr}(\mathrm{VI})$, increasing the $\mathrm{pH}$ was reported to lead to a decrease in the $\mathrm{Cr}$ adsorption on the biochar surface. This was attributed to the $\mathrm{OH}-$ competition with $\mathrm{Cr}(\mathrm{VI})$ species to bind to the active/charged sites at the biochar's surface. Thus, the removal of $\mathrm{Cr}(\mathrm{VI})$ was dictated by the $\mathrm{pH}$ as reported by Shang et al. (2017).

The $\mathrm{pH}$ of the solution also affects the adsorption capacity of organic contaminants of industrial wastewater. The adsorption of textile dyes in wastewater using biochar produced from food waste was investigated by Parshetti et al. (2013). They observed that an alkaline $\mathrm{pH}$ enhanced the adsorption of dyes. It was attributed to the high interaction between the negatively charged sites on the biochar's surface with the positively charged dyes. In contrast, at $\mathrm{pH} 3$, its efficiency to adsorb organic dye decreased because of the existence of extra $\mathrm{H}^{+}$ that compete with the positive charges of the dye. Tsai and Chen (2013) and Xu et al. (2011) reported similar observations on the effect of the $\mathrm{pH}$ on the adsorption capacity of biochar. Thus, the $\mathrm{pH}$ of the solution affects the adsorption capacity of organic compounds and inorganic pollutants from industrial wastewater on biochar by altering the charged sites.

\section{Amount of biochar}

The adsorption capacity is also affected by the amount of biochar. Chen et al. (2011a, b) studied the removal of potentially toxic metals $(\mathrm{Cd}, \mathrm{Cu}, \mathrm{Pb}$ and $\mathrm{Zn})$ from industrial wastewater using biochar prepared from hardwood and corn straw. They observed an improvement of the adsorption efficiency of the toxic metals when the concentration of the biochar increased from 0.5 to $5 \mathrm{~g} / \mathrm{L}$. It was attributed to an increase in the number of active sites and surface area by increasing the amount of biochar. This observation is in agreement with the reports of Lalhruaitluanga et al. (2010), Tsai and Chen (2013) and recently by Lu et al. (2017). Moreover, Sun et al. (2013a, b) reported that increasing the dose of biochar (prepared from swine manure) from 1 to $8 \mathrm{~g} / \mathrm{L}$ las to increase the active sites available to adsorb methylene blue. Wang et al. (2018) found similar results by increasing the biochar amount for the adsorption of organic pollutants. A high concentration of biochar has a positive impact on the adsorption of organic pollutants and potentially toxic elements. It would be therefore useful to find the optimum dose, which is a key factor to minimize the biochar production costs in view of its industrial application.

\section{Management and regeneration of exhausted biochar}

During the regeneration of biochar, the adsorbate can be recovered using the principle of decomposition and desorption (Jia et al. 2013; Wang et al. 2015). Adsorbents for the removal and degradation of pharmaceutical compounds were prepared by ball milling. Hybrid activated carbon and biochar functionalized with $\mathrm{Fe}_{3} \mathrm{O}_{4}$ showed that magnetically separable biochar degraded $97 \%$ of tetracycline in water compared to the low adsorption of this compound on activated carbon. The regeneration of this adsorbent depended on the adsorbents' origin, method of regeneration as well as the dose of the adsorbents. Similar results were also reported by Wang et al. (2015) who prepared magnetic biochar from leaves residues of eucalyptus for the degradation of organic pollutant. They showed that there is no change in band shift of the Fourier transform infrared spectroscopy spectra until 6 cycles. This was attributed to an increase in the ash content of the biochar as well as to the non-significant change in the functional groups present on its surface. Regenerated magnetic biochar presented similar surface area and pore sizes as the as-prepared biochar allowing high adsorption and/or separation rates. The regeneration of the adsorbent makes the adsorption process economic. However, the use of water for regeneration is not an efficient method. Chemical regeneration should be considered. It involves reagents such as $\mathrm{NaOH}$. It can also be carried out by a change of the adsorbent's $\mathrm{pH}$ in order to desorb the non-reactive chemicals like aniline and dyes (Fagbohungbe et al. 2017). Some the chemical reagents used for regeneration are costly and may pollute the environment to a high extent. For this reason, the process disposal of the digestate is a key factor in the management of biochar. The graphical representation of biochar to adsorb contaminants from wastewater, the regeneration of biochar, and other treatment processes, are shown in Fig. 4. 
One of the best methods for the regeneration of biochar is thermal regeneration. It allows the formation of small pore sizes compared to the original pores of the used biochar, especially when it is applied at high temperatures. The authors observed also that the efficiency of the regeneration increases with increasing the temperature. Qiao et al. (2018) compared the adsorption rates of organic compounds, such as pyrene and benzopyrene, using Enteromorpha prolifera biochar. They observed that the adsorption efficiency increased by $35.0 \%, 45.0 \%$ and $48.0 \%$ for pyrene and by $31.0 \%, 41.0 \%$ and $40.0 \%$ for benzopyrene after regeneration at $80{ }^{\circ} \mathrm{C}, 150{ }^{\circ} \mathrm{C}$ and $200{ }^{\circ} \mathrm{C}$, respectively. Also, they observed that biochar regeneration using the thermal method can also reduce the dissolved organic carbon.

Microwave (MW) irradiation was also used for biochar regeneration. It was shown that it allows a fast regeneration of biochars. Furthermore, using this method, the operating temperature can be easily controlled. MW irradiation was also seen to induce polar molecules in the biochar producing dipole/polarization. However, this method remains at laboratory scale and in the experimental stage and is not currently applied on large scale (Ania et al. 2005; Jia et al. 2013; Li et al. 2018). Otherwise, Dai et al. (2019) investigate biochar regeneration by adjusting the operating pressure using supercritical fluid. The author showed high volatile organic compounds (VOCs) adsorption without changing the chemical and physical properties of the biochar. This operation was shown to fulfil low biochar loss, low operating temperatures and a short operating cycle. However, this method remains also in the experimental stage and not applied on large scale due to the high cost of the material equipment, high-pressure resistance and its complexity.

In conclusion, from all methods for management and regeneration of biochar, thermal regeneration is seen to be the more mature regeneration process with low cost and high economic applicability. However, a high carbon loss was observed compared with other regeneration methods. More research should be carried out in the future focusing on the economic aspect of the biochar uses.

\section{Treatment of typical pollutants}

Due to its capacity to adsorb pollutants in the liquid phase (Chen et al. 2011a, b), biochar has been extensively explored for water/wastewater treatment. As summarized by Chen et al. (2011a, b), it is mostly used for the adsorption of potentially toxic metals (46\%) and organic pollutants (39\%). It can also be used for the adsorption of phosphorus and nitrogen (13\%). The remaining $2 \%$ is for adsorption of other pollutants because of its large specific surface area, porous structure and surface functional groups.

\section{Adsorption isotherm}

The discharge of organic and inorganic pollutants in industrial effluents is becoming a universal problem. Scientists applied biochar to remove these toxic pollutants from aqueous solution. Table 2 summarizes the use of biochar for the

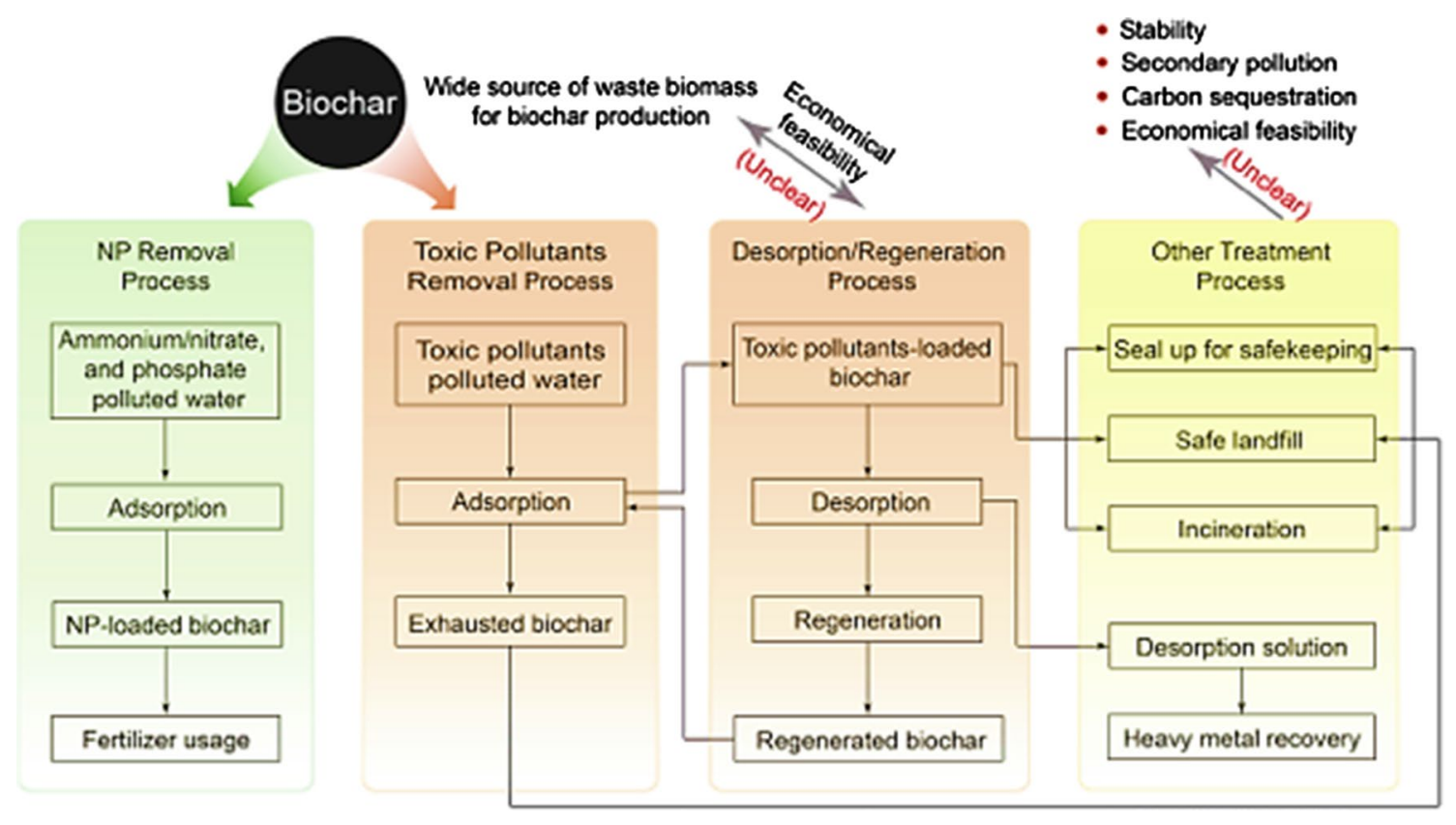

Fig. 4 The graphical representation of wastewater contaminants' adsorption on biochar and the possible ways of its regeneration (Adapted from Mubarak et al. 2016) 
adsorption of pollutants in water. Thus, it is necessary to quantify and optimize the interaction between the adsorption capacity of the biochar with the adsorbates through the adsorption isotherms at constant ambient temperature (Fan et al. 2017; Goh et al. 2008; Kołodyńska et al. 2012). Different empirical equilibrium models such as Temkin equations, Langmuir-Freundlich, Freundlich and Langmuir were applied to describe the equilibrium of organic and inorganic pollutants adsorption to biochar. The results showed that the adsorption equilibrium isotherms depend upon the binding affinity of the pollutants on the surface of the biochar. Freundlich and Langmuir isotherm models showed the best fit models than other models during the quantification of the adsorption of inorganic pollutants on biochar. These models consider only one layer of the adsorption of the adsorbate on the homogeneous surface of adsorbent during the binds (Aydın and Aksoy 2009). Chen et al. (2011a, b) investigated the Langmuir-Freundlich model for the adsorption of $\mathrm{Cu}^{2+}$ and $\mathrm{Zn}^{2+}$ at different concentrations. The results showed that the Langmuir model fitted the experimental data $(R 2>0.998)$ when compared to the Freundlich model ( $R 2$ were $0.86-0.94$ ). This model considers one single site of the adsorbate binds with one molecule of adsorbate in a homogeneous surface during the binding affinity. Similar results were reported by Tong et al. (2011). They compared the fit of models such as Freundlich, Langmuir as well as Temkin for the adsorption of $\mathrm{Cu}^{2+}$ using three different biochar materials. They showed that the Langmuir model exhibited the highest fit of the data when compared to the other models, Freundlich and Temkin. Recently, the dynamic adsorption of heavy metals using biochar showed that the Freundlich model showed the highest fit than Langmuir isotherm (Kołodyńska et al. 2012; Lu et al. 2012; Xu et al. 2013; Zhang et al. 2013a, b). According to Freundlich isotherm, the model assumed one molecule with multiple types of sites during the affinity of the adsorbate on the adsorbent. In another study, Zhang et al. (2013a, b) studied the adsorption of $\mathrm{Pb}^{2+}$ and $\mathrm{Cr}^{3+}$ using biochar prepared from wastewater sludge. This biochar showed that the adsorption of $\mathrm{Pb}^{2+}$ fitted the Langmuir model, whereas the adsorption of $\mathrm{Cr}^{3+}$ fitted the Freundlich model. This result indicates that Freundlich isotherm has multiple sites as well as it is not restricted to one site like Langmuir for the adsorption pollutants.

Biochar has a high affinity towards organic pollutants. Table 3 summarizes the high performance of biochar derived from biomass in removing organic pollutants such as pesticides, antibiotics, herbicides and dyes. The adsorption of the organic pollutants fitted the model of Langmuir and

Table 2 Adsorption capacities of different biochars for inorganic contaminants from industrial wastewater

\begin{tabular}{|c|c|c|c|c|c|c|}
\hline Type of biochar & $\mathrm{pH}$ & Temp. $\left({ }^{\circ} \mathrm{C}\right)$ & Targeted species & Con. range $(\mathrm{mg} / \mathrm{L})$ & $\begin{array}{l}\text { Langmuir adsorp- } \\
\text { tion capacity } \\
(\mathrm{mg} / \mathrm{g})\end{array}$ & References \\
\hline Pinewood char & 5 & 25 & $\mathrm{~Pb}^{2+}$ & $2-1036$ & 4.13 & Mohan et al. (2011) \\
\hline Celery & 5 & 25 & $\mathrm{~Pb}^{2+}$ & $270-305$ & & Zhang et al. (2017) \\
\hline Peanut straw char & 4.5 & 25 & $\mathrm{Cu}^{2+}$ & $6-318$ & 12.52 & Mubarak et al. $(2013 a, b)$ \\
\hline Soybean straw char & 4.5 & 25 & $\mathrm{Cu}^{2+}$ & $158-954$ & 33 & Tong et al. (2011) \\
\hline Rice husks & 5 & 24 & $\mathrm{Cu}^{2+}$ & $1-20$ & 3.49 & Pellera et al. (2012) \\
\hline Pig manure biochar & 5 & 20 & $\mathrm{Zn}^{2+}$ & $0.065-0.2$ & 62.13 & Kołodyńska et al. (2012 \\
\hline Cow manure biochar & 5 & 20 & $\mathrm{Zn}^{2+}$ & $0.06-0.2$ & 58.11 & Kołodyńska et al. (2012 \\
\hline Dairy manure biochar & - & - & $\mathrm{Cu}^{2+}$ & $0-318$ & 48.11 & Xu et al. (2013) \\
\hline Dairy manure biochar & - & - & $\mathrm{Zn}^{2+}$ & $0-327$ & 32.95 & Xu et al. (2013) \\
\hline Dairy manure biochar & - & - & $\mathrm{Cd}^{2+}$ & $0-6575$ & 32.03 & Xu et al. (2013) \\
\hline Oak Wood char & 2 & 25 & $\mathrm{Cr}^{6+}$ & $1-100$ & 3.03 & Mohan et al. (2014) \\
\hline Sugar beet tailing biochar & 2 & 22 & $\mathrm{Cr}^{6+}$ & $50-800$ & 123 & Dong et al. (2011) \\
\hline Coconut coir derived char & 3 & 25 & $\mathrm{Cr}^{6+}$ & $10-500$ & - & Kim et al. (2012) \\
\hline Pine needle biochar & 6 & 25 & $\mathrm{U}^{6+}$ & $5-30$ & 2.12 & Park et al. (2011) \\
\hline Corn straw & 5 & 22 & $\mathrm{Hg}^{2+}$ & $0-139$ & - & Wang et al. (2018) \\
\hline Pinewood biochar & 2 & 25 & $\mathrm{~F}^{-}$ & $1-100$ & 7.66 & Ahmad et al. (2012) \\
\hline Digested sugar beet tailing biochar & 7 & 22 & $\mathrm{PO}_{4}^{3-}$ & $15-640$ & 133.085 & Yao et al. $(2011 \mathrm{a}, \mathrm{b})$ \\
\hline undigested sugar beet tailings & 7 & 22 & $\mathrm{PO}_{4}^{3-}$ & 61.5 & - & Yao et al. (2011a, b) \\
\hline Orange peel biochar & - & 25 & $\mathrm{PO}_{4}^{3-}$ & $0-12$ & 0.007 & Chen et al.a (2011) \\
\hline Banana peels & 5 & 25 & $\mathrm{Cu}^{2+}$ & $60-80$ & 38.2 & Ahmad and Gao (2018) \\
\hline Banana peels & 6 & 22 & $\mathrm{~Pb}^{2+}$ & $70-250$ & 87.5 & Ahmed et al. (2018) \\
\hline Corn straw & 5 & 22 & $\mathrm{As}^{3+}$ & $0-7$ & - & He et al. (2018) \\
\hline Corn straw & 5 & 22 & $\mathrm{Hg}^{2+}$ & 140 & 5.03 & Wang et al. (2018) \\
\hline
\end{tabular}


Freundlich (Ahmed et al. 2016; Chen et al. 2012; Jung et al. 2013; Kah et al. 2017; Li et al. 2018; Lima 2018). Ahmad et al. (2012) reported on the removal of trichloroethylene from water using biochar derived from crop residues. They showed that the experimental adsorption of the trichloroethylene fitted to the Langmuir model. Similar results were reported for the adsorption of methylene blue using biochar prepared from different biomass (Sun et al. 2013a, b). In contrast, Yao et al. (2013a, b) demonstrated that the adsorption of fluoroquinolone antibiotics on biochar derived from the sludge of wastewater fitted the Freundlich model. In general, the use of biochar as adsorbent for the removal of organic and inorganic pollutants from water showed high performance. Moreover, the binding affinity of the biochar with the contaminants depended on the physicochemical properties of the biochar.

\section{Adsorption kinetics}

The chemical and physical properties of the biochar can drastically affect the adsorption behaviour of biochar towards organic and inorganic pollutant. These properties affect the adsorption kinetics and mechanism involving chemical binding as well as mass transport (Boutsika et al. 2014; Inyang et al. 2012; Xu et al. 2013). Reddy and Lee (2013) reported that to apply biochar in large scale for the removal of organic and inorganic pollutants from wastewater, it is necessary to clearly know the adsorbent surface area, diffusion mechanisms and chemical reaction involved in the adsorption process thorough the intra-particle diffusion model. Most kinetic properties that were studied for the removal of pollutants mediating biochar fitted a pseudo-second-order kinetic model due to a rate-limiting step involving chemical sorption (Mohan et al. 2011). Biochar derived from sewage sludge was used by $\mathrm{Lu}$ et al. (2012) to adsorb $\mathrm{Pb}^{2+}$ from water in the range of $\mathrm{pH}$ from 2 to 5 . They showed that the kinetics fitted the pseudo-second-order model due to a chemisorption of the $\mathrm{Pb}^{2+}$ on the biochar. Liu and Zhang (2009) studied the adsorption mechanism of $\mathrm{Pb}^{2+}$ on biochar prepared from biomass of pinewood and rice husk. Their mechanism showed that their kinetics fitted the pseudo-second-order model because the chemical adsorption was considered as the ratelimiting step (Jia et al. 2013). Likewise, oxytetracycline and methylene blue sorption on biochar produced from biomass of palm bark, maize straw and eucalyptus was seen to fit the pseudo-second-order kinetic model (Sun et al. 2013a, b).

\section{Heavy metal pollutants}

Heavy metals are the most significant contaminants resulting from industries, whereby the presence of very small amounts of heavy metals such as $\mathrm{Cd}, \mathrm{Cu}, \mathrm{Zn}$ and $\mathrm{Pb}$ in wastewater causes a significant effect on the environment. Adsorption of heavy metals on materials like biochar before discharging the treated water can reduce their concentration before reaching

Table 3 Adsorption capacities of different biochars towards organic contaminants from industrial wastewater

\begin{tabular}{|c|c|c|c|c|c|c|}
\hline Type of biochar & $\mathrm{pH}$ & Temp. $\left({ }^{\circ} \mathrm{C}\right)$ & Targeted species & $\begin{array}{l}\text { Concentration } \\
\text { range }(\mathrm{mg} / \mathrm{L})\end{array}$ & $\begin{array}{l}\text { Langmuir adsorp- } \\
\text { tion capacity } \\
(\mathrm{mg} / \mathrm{g})\end{array}$ & References \\
\hline P-(acrylamide)-wood biochar & - & 25 & Phenol & $5-50$ & 23.14 & Karakoyun et al. (2011) \\
\hline Rice husk biochar & - & 40 & Phenol & $100-15,000$ & 409.8 & Liu et al. (2011) \\
\hline $\begin{array}{l}\text { Hardwood (Laurel oak, } \\
\text { Quercus) }\end{array}$ & - & - & Humic acid & $0-13$ & - & $\begin{array}{l}\text { Mukherjee and Zimmerman, } \\
\text { (2013) }\end{array}$ \\
\hline Orange peel biochar & - & 25 & Naphthalene & 18 & - & Zhou et al. (2014) \\
\hline Wood char & 7 & 25 & Pyrene & $0.002-0.12$ & - & Peng et al. (2011) \\
\hline Pine needle biochar & - & - & m-dinitrobenzene & $0.02-1.0$ & - & Chen and Chen, (2009) \\
\hline Peanut straw char & $5-9$ & 25 & methyl violet & $40-816$ & 104.61 & Xu et al. (2011) \\
\hline kenaf fibre char & 8.5 & 30 & methylene blue & $50-200$ & 18.18 & Xu et al. (2011) \\
\hline Rice straw-derived char & 5 & 30 & Malachite green & $25-300$ & 128.14 & Han et al. (2015) \\
\hline Bamboo biochar & 1 & 40 & Acid black 172 & $50-500$ & 358.14 & Han et al. (2015) \\
\hline Sewage sludge/ & & & 2,4-Dichlorophenol & $100 \%$ removal & - & Kalderis et al. (2017) \\
\hline Corn straw & 5 & 22 & Bisphenol & 500 & - & Zhao et al. (2017) \\
\hline $\begin{array}{l}\text { Dissolved black carbon biochar } \\
\text { (DBC) }\end{array}$ & 5 & 25 & Naphthalene & 91 & - & Fu et al. (2018) \\
\hline Miscanthus-derived biochar & 5 & 30 & Naphthalene & $4-35$ & - & Kim and Hyun (2018) \\
\hline Bamboo hydrochars & 1 & 35 & Congo red & 100 & - & Li et al. (2018) \\
\hline Sugarcane bagasse biochar & 7 & 25 & Malachite green & 3000 & - & Vyavahare et al. (2018) \\
\hline Corn straw & 5 & 22 & Atrazine & 70 & - & Zhang et al. (2018) \\
\hline Macadamia nutshells & 7 & 30 & Phenanthrene & 60 & - & Yang et al. (2018) \\
\hline
\end{tabular}


the environment. Biochar has a high ability to adsorb inorganic pollutants like heavy metals upon different interaction mechanisms such as physical adsorption, precipitation, ion exchange and electrostatic attraction. The mechanisms involved in the adsorption of heavy metals and their interaction are described in Fig. 1a, and the adsorption capacities of various biochar for heavy metals are given in Table 2 .

Dong et al. (2011) studied the interaction mechanisms of $\mathrm{Cr}(\mathrm{VI})$ with biochar produced from sugar beet leading to the formation of $\mathrm{Cr}$ (III). They showed that positive charges of the biochar are electrostatically attracted towards the negative charge of $\mathrm{Cr}(\mathrm{VI})$ species. Also, they showed that hydrogen ions coming from the biochar are involved in the reduction of $\mathrm{Cr}(\mathrm{VI})$ to $\mathrm{Cr}(\mathrm{III})$. The reduced $\mathrm{Cr}(\mathrm{III})$ reacts with the functional groups of the biochar in aqueous solution to form a complex of $\mathrm{Cr}(\mathrm{III})$. Similar findings were reported by $\mathrm{Lu}$ et al. (2012), who worked on the adsorption of $\mathrm{Pb}^{2+}$ from wastewater using biochar prepared from sewage sludge; they showed that the functional groups of the biochar are crucial to forming a complex with $\mathrm{Pb}$. Similar mechanism was also shown by Kong et al. (2011) and Sun et al. (2014) in adsorbing $\mathrm{Hg}$ (II) using biochar derived from soybean stalk and adsorption of $\mathrm{Cd}$ (II) using biochar produced from corn straw.

Moreover, another parameter that affects the adsorption of heavy metals like $\mathrm{Pb}, \mathrm{Cu}, \mathrm{Zn}$ and $\mathrm{Cd}$ is the composition of the feedstock. Although prepared at the same pyrolysis temperature, biochars obtained from different feedstocks exhibit different adsorption capacity of heavy metals (Sun et al. 2014). It should be related to the presence and absence of minerals like $\mathrm{CO}_{3}^{2-}, \mathrm{PO}_{4}^{3-}$ in the feedstock, which affects the adsorption capacity of biochar. These minerals can contribute to the formation of active sites that enhance the adsorption of heavy metals from wastewater (Cao et al. 2009; Xu et al. 2013).

\section{Treatment of organic pollutants}

Organic pollutants such as phenols, antibiotics, herbicides can be highly adsorbed onto biochar (Chen et al. 2011a, b). In livestock wastewater, similar organic contaminants and pollutants are always found; as a result, biochar has become a major focus in agricultural resources and the environment. Table 3 summarizes the application of biochar in the adsorption of organic pollutants, and the various mechanisms involved are described in Fig. 3b.

Antibiotic substances such as a fluoroquinolone, sulfamethoxazole can be adsorbed by biochar in their aqueous phase mainly through hydrogen bonding, $\pi-\pi$ electron transition and cationic interactions. For example, the fluoroquinolone adsorption ability of biochar was investigated by Hale et al. (2012). Their biochar was prepared using pyrolysis of sludge at $500{ }^{\circ} \mathrm{C}$ for $1 \mathrm{~h}$, and the maximum adsorption capacity was $19.8 \pm 0.4 \mathrm{mg} / \mathrm{g}$. It was also found that the adsorption of fluoroquinolones was positively correlated with the amount of volatile matter contained in the raw sludge. Similar results were reported by Bartoli et al. (2016) to produce biochar from Arundo donax using microwave-assisted pyrolysis to adsorb sulfamethoxazole. They observed that increasing the pyrolysis temperature decreased the adsorption capacity of biochar. It was reported that biochar has a significant impact on the adsorption of organic pollutants, such as phenols, compounds with high-chromatic content, herbicides (Inyang et al. 2011; Klasson et al. 2013).

The mechanism of adsorption can be either physical or chemical. It dependents mainly on the aromatic and/or special functional groups and on the polarity of both the biochar and the organic pollutants. The nature of intermolecular gravitation and electrostatic force between the biochar and the pollutants is the determining factor for the physical adsorption, while the chemical adsorption mainly depends on the chemical interactions between the biochar and the organic pollutant, which can be $\pi$ bonds, hydrogen bonds and coordination bonds (Liu and Zhang 2009). Liu and Zhang (2009) prepared biochar from different raw materials (cole, peanut and rapeseed straw) after pyrolyzing at $350^{\circ} \mathrm{C}$. The methyl violet adsorption capacity of their biochar was in the range of $123.5-195.4 \mathrm{mg} / \mathrm{g}$. Rapeseed straw gave the highest adsorption at room temperature. The presence of electrostatic attraction between methyl violet and biochar was confirmed by zeta potential and FTIR analysis. The results revealed that the methyl violet was mainly adsorbed on the hydrophilic andCOO-sites. Mohan et al. (2014) obtained methyl blue removal efficiency of 99.5, 99.3 and $86.1 \%$ using biochar prepared from anaerobic digestion residue, palm bark and tree, respectively. The organic materials were pyrolysed at $400{ }^{\circ} \mathrm{C}$ for $30 \mathrm{~min}$, and the conditions during the treatment were $\mathrm{pH} 7,40^{\circ} \mathrm{C}$ and $4 \mathrm{mg} / \mathrm{L}$ of the dye. It was found that the pyrolysis temperature had a significant effect on the treatment of methyl violet.

Mohn et al. (2014) prepared biochar from peanut shells and wheat straw and obtained a maximum adsorption capacity of 58.82 and $20.61 \mathrm{mg} / \mathrm{g}$, respectively. These organic materials were pyrolysed at 400 and $600{ }^{\circ} \mathrm{C}$, respectively. The adsorption capacity of biochar prepared from mixed wood wastes, pyrolysed at $450{ }^{\circ} \mathrm{C}$ for $1 \mathrm{~h}$, was investigated, and maximum adsorption capacities of 1066 and $1158 \mathrm{mg} / \mathrm{g}$ were obtained for two herbicides, namely simazine and atrazine, respectively (Qiu et al. 2009). The authors claimed that better adsorption performances were obtained in acidic conditions.

\section{Treatment of nitrogen and phosphorus contamination}

Other than the above organic and heavy metal pollutants, biochar has been also tested to remove nitrogen and phosphorus from industrial wastewater to reduce the impact of eutrophication on the ecosystem. The digestate left after this process can be used as high-quality fertilizer (Zhang et al. 2013a, b; Hale et al. 2012). Using biochar produced from 
cow dung to remove $\mathrm{PO}_{4}-\mathrm{P}$ and $\mathrm{NH}_{4}-\mathrm{N}$ from wastewater. Wang et al. (2014) observed high adsorption capacity. They also found that the biochar feedstock dictated the adsorption capabilities towards nitrogen and phosphorus. Therefore, biochar has a high capacity to remove $\mathrm{PO}_{4}-\mathrm{P}$ and $\mathrm{NH}_{4}-\mathrm{N}$ allowing to release nutrients to increase soil fertility, which contributes to increasing crops' production.

\section{Biochar-supported catalysts for wastewater treatment}

Biochar can be used as a support for catalytic nanoparticles to take advantage of their exceptional properties such as high electrical conductivity, chemical stability, having functional groups that can easily be tuned and unique surface properties (Cuong et al. 2019; Liu et al. 2015; Xia and Larock 2010). Kim and Kan (2016) investigated the degradation of sulfamethoxazole from wastewater through biochar-supported $\mathrm{TiO}_{2}$ photocatalyst material. Results showed that the biochar loaded with $\mathrm{TiO}_{2}$ has high adsorption efficiency towards sulfamethoxazole when compared to the commercial nanoparticles. This was attributed to the biochar's electron conductivity decreasing the recombination of the electron/hole pairs during the photocatalysis. Furthermore, this enhances the charge balance at the surface of the biochar (functional groups) to adsorb various contaminants from the wastewater. For this reason, researches carried out synthesis of various biochar-supported photocatalysts such as $\mathrm{TiO}_{2}$ hybrid with Miscanthus straw pellets and softwood pellets, $\mathrm{TiO}_{2}-$ corn cob, $\mathrm{TiO}_{2}$-waste plum, $\mathrm{TiO}_{2}$-wheat husks, $\mathrm{TiO}_{2}$-chitosan, $\mathrm{TiO}_{2}$-reed straw, $\mathrm{TiO}_{2}$-bamboo, graphitic carbon nitride/ $\mathrm{FeVO}_{4}$-pine needles, graphitic carbon nitride-chestnut, $\mathrm{ZrO}_{2}$-wheat husks, $\mathrm{BiOX}$-biochar and $\mathrm{TiO}_{2}$-wood charcoal. These combinations and others showed that these biochar-supported photocatalytic nanoparticles exhibited high efficiency for the degradation of different pollutants under visible light radiation. Such hybrid materials have been reported with high chemical stability as well as high recollection ability (Colmenares et al. 2016; Kalaivani and Suja 2016; Khataee et al. 2017a, 2017b; Kim and Kan 2016; Kumar et al. 2017; Li et al. 2016; Lisowski et al. 2017; Liu et al. 2017; Luo et al. 2015; Matos et al. 2013a, 2013b; Pi et al. 2015; Wu et al. 2015; Zhang et al. 2017).

\section{Removal of organic pollutants from wastewater using biochar-supported catalysts}

Biochar-supported photocatalytic materials can be used for different applications. One of the most promising applications of biochar-supported photocatalytic material is removing organic pollutants from the wastewater. This may be due to its high surface area and highly oxidative reactive species enhancing the adsorption capacity during the photodegradation process. As shown in Table 4, there are different types of biochar-supported photocatalysts, and many studies have been carried out in the past ten years for the removal of organic pollutants. The results showed the high efficiency for the degradation of methylene blue, phenol and sulfamethoxazole. Its adsorption capacity is equal to $400 \mathrm{ppm}, 50 \mathrm{ppm}$ and $10 \mathrm{ppm}$, respectively, when compared with nanoparticles only. According to Lisowski et al. (2017), a reactor loaded with softwood pellets- $\mathrm{TiO}_{2}$ significantly mineralized methanol into methyl formate and carbon dioxide due to the generation of highly reactive species such as $\mathrm{OH}$ and $\mathrm{O}_{2}^{-}$and $\mathrm{h}^{+}$as shown in Fig. 5. Moreover, they claimed that the biocharsupported $\mathrm{TiO}_{2}$ can act also as electrodes as well as it can act as the water splitting during hydrogen production. J. Matos (2016) reported a comparison of the efficiency of the biochar-supported $\mathrm{Au}-\mathrm{TiO}_{2}$ for the degradation of organic pollutants. It showed that the biochar-supported $\mathrm{Au}-\mathrm{TiO}_{2}$ composite has higher efficiency for the degradation of the organic pollutants than the nanoparticles by themselves. This can be attributed to the presence of the oxygen-containing groups on the biochar surface leading to reduce the photo-generated charge recombination and thus to enhance the pollutants' degradation. Also, the biochar-supported photocatalytic material has high stability when compared to the commercial nanoparticle.

The incorporation of nanoparticles onto the biochar can:

- increase the physicochemical properties of the nanoparticles,

- increase their active sites,

- shuttle electrons through a graphene-like skeleton,

- act as electron reservoir which conducts away the electron from the $\mathrm{e}^{-} / \mathrm{h}^{+}$,

- reduce the bandgap energy by carbon or other non-metal doping (impurities or dangling bonds) improving the charge separation when compared with bare catalytic nanoparticles.

For this reason, it has high performance in degradation and absorption of the organic pollutants in aqueous solution. However, there are some aspects to be further investigated in the future for the development of highly efficient biocharsupported photocatalysts such as:

- the use of different biomass and nanoparticles,

- the heating/operating conditions,

- the ratio of biomass to nanoparticles,

- the use of other waste materials such as manure and sewage sludge composite with nanoparticles. 
Table 4 Application of various biochar-supported photocatalysts

\begin{tabular}{llll}
\hline Type of biochar-nanoparticles catalysis & Targeted species & $\begin{array}{l}\text { Concentration } \\
\text { range (mL- } \\
\text { mg/L) }\end{array}$ & References \\
\hline Starbon- $\mathrm{TiO}_{2}$ & Phenol & $150-50$ & Colmenares et al. (2013) \\
Softwood pellets- $\mathrm{TiO}_{2}$ & Phenol & $150-50$ & Lisowski et al. (2017) \\
Pinewood- $\mathrm{TiO}_{2}$ & Bisphenol & $50-20$ & Luo et al. (2015) \\
Waste plum stones-N-TiO & Methylene blue & $125-25$ & Matos et al.(2013b) \\
Bamboo- $\mathrm{TiO}_{2}$ & Methylene blue & $200-30$ & Wu et al. (2015) \\
Chestnut leaf- $g-\mathrm{C}_{3} \mathrm{~N}_{4}$ & Methylene blue & $20-4.8$ & Pi et al. (2015) \\
Sludge/wheat husks-TiO & Reactive Blue 69 & $1-20$ & Khataee et al. (2017a) \\
Reed straw- $-\mathrm{TiO}_{2}$ & Sulfamethoxazole & $160-10$ & Zhang et al. (2017) \\
Corn cob- $-\mathrm{TiO}_{2}$ & Sulfamethoxazole & $100-10$ & Kumar et al. (2017) \\
\hline
\end{tabular}

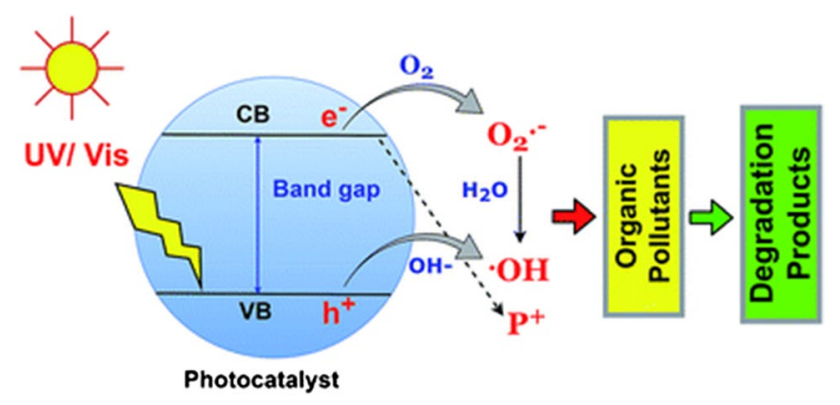

Fig. 5 Fundamentals of organic pollutant photodegradation by reactive oxygen species

These trends can improve the performance of the biocharsupported photocatalysts for the degradation and removal of recalcitrant/emerging organic pollutants from aqueous solution.

\section{Economic and environmental benefit analyses}

As seen from the above-reviewed literature, biochar has a huge application potential in the removal of industrial pollutants. However, prior large-scale application, some parameters should be optimized to improve the economic viability of the process, namely the type of biochar, local availability of the source material, pyrolysis temperature, availability of industrial-scale reactors, regeneration method and life span.

Given a maximum benefit for the users and a long-term manufacturing for the industry, Dai et al. (2019) observed that biochars produced using slow and fast pyrolysis conditions have costs of 18.30 and $8.14 \mathrm{US} \$ /$ ton, respectively. Also, a survey made by the International Biochar Initiative (IBI) in 2013 reported that the average price of biochar is globally in the range of 80.00 US $\$$ /ton to $13,480.00$ US $\$$ ton at sellers' company. However, a recent survey made in the
USA from 23 biochar companies reported an average price of 2512.00 US\$/ton. Currently, the International Biochar Initiative and the European Biochar Certificate are establishing a standards' chart for the development of biochar as recently reported by Dai et al. (2019).

In general, the application of biochars for the removal of pollutants was discussed in detail in the past years. However, the research on biochar market/price is in an early stage so that more research must be carried out in the future to analyse the significant differences in the biochar prices and their economic benefits, to apply at large scale for the removal of pollutants.

The application of biochar to mitigate the impact of climate change and to enhance sustainable agricultural and environmental development is a new approach (Oliveira et al. 2017). Currently, the world still faces the environmental impact of greenhouse gases and global warming (Wang et al. 2018). Environmental issues and the reduction of greenhouse gases (GHG) are the driving forces for research to develop new environmentally friendly mitigate materials to immobilize carbon from the active cycle and return it to an inactive cycle using biochar. Liu et al. (2015) showed that $\mathrm{CO}_{2}$ emission can be reduced in the range of $0.10-0.30$ billion tons/year using biochar. This shows that biochar can contribute to reducing the concentration of atmospheric $\mathrm{CO}_{2}$, which leads to GHG's emission reduction. Otherwise, Dai et al. (2019) reported that $\mathrm{N}_{2} \mathrm{O}$ emissions could be reduced by biochar-modified soil. Indeed, the greenhouse effect of $\mathrm{N}_{2} \mathrm{O}$ is 310 times higher than that of $\mathrm{CO}_{2}$.

In the last two decades, a lot of studies dealt with biochar applications related to soil amendment, waste management, climate change and energy production as shown in Fig. 6.

This technology involves 4 complementary and often synergistic social and financial uses, namely:

- soil improvement (to improve productivity as well as to reduce pollution toxicity),

- climate change mitigation, 
- energy production and

- waste management.

However, the application of biochar to remove organic or inorganic contaminants and other environmental activates depends upon the type of biochar used as shown in Fig. 7.

Based on the pyrolysis of biomass, biochar was reported to sequester carbon in soil, to capture $\mathrm{CO}_{2}$ from the atmosphere and to generate biogas. In order to achieve the sequestration of carbon in the soil, biochar should be able to remain for long time in the soil. This longevity is principally related to the mineralization of the biochar over many years. It is worth to investigate the relationship between the preparation method/conditions, the feedstock, the microstructure and the biochar stability over decades. Many techniques can be used to assess the biochar mineralization over time such as infrared spectroscopy, biomarkers, nuclear magnetic resonance among others (Weldon et al. 2019; Medyńska-Juraszek et al. 2020). However, one cannot omit the ecotoxicological effects that may arise from the mineralization from the biochar itself. This specific point needs deep investigation.

\section{Future perspectives}

It has been demonstrated that biochar is a promising material for water treatment and agricultural soil fertility maintenance and remediation. However, studies dedicated to the contribution of biochar to the removal of contaminants from wastewaters, the influence of different feedstock sources on

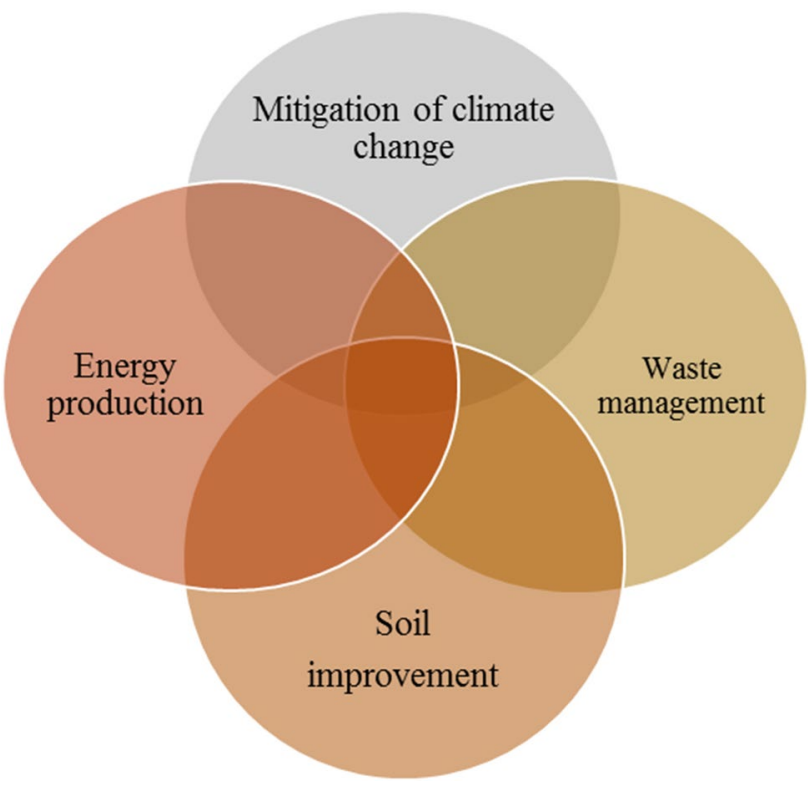

Fig. 6 Social and financial involvements of biochar technology (adapted from Joseph et al. 2010) biochar quality and physicochemical factors affecting the contaminants removal efficiency remain on an initial stage. Therefore, the following research areas should be considered in the near future:

1. Establishing the model for a modified biochar adsorption mechanism. It is crucial to modify the surface functionality and the porosity according to the application. To do so, processes such as amination, sulfonation, surface oxidation and pores' structure modification can bring new insights to the preparation of selective biochar materials.

2. Developing modified methods to improve adsorption efficiency. Many trials should be done to explore other modifiers or activators, which impact the efficiency of biochars to remove organic and inorganic pollutants.

3. It would be useful to find the optimum dose and method for biochar production allowing it to rapidly remove various contaminants from wastewater. These are key factors to apply for large-scale implementation in order to minimize the biochar production and utilization costs.

4. The economic visibility of biochar and its regeneration and standard operating methods in removing toxic pollutants from industrial wastewater are needed today. Biochar's pre-treatment for the removal of toxic compounds and subsequent biological treatment need more investigation before possible implementation on a large scale.

5. Biochar activated with chemicals showed high adsorption capacity to remove pollutants if compared to nonactivated ones. However, absorption mechanisms need further investigation.

In general, only a few studies were conducted in these areas, so that further research is required on topics related to the relationship between raw materials, processing parameters, as well as on the biochar regeneration to avoid environmental risks as shown in Fig. 8.

\section{Conclusion}

The review shows that biochar has broad prospects for the removal of typical organic and inorganic pollutants present in industrial wastewater. It is an interesting type of adsorbent with high efficiency. It is an eco-friendly sorbing material owing to its large surface area, charged surface and functional groups. Biochar showed a great potential to adsorb inorganic and organic pollutants involving various mechanisms such as pore filling, electrostatic interactions, ion exchange, precipitation and surface sorption, which are dependent upon the physiochemical characteristics of biochar such as biochar dosage, pyrolysis temperature and the $\mathrm{pH}$ of the treated matrix. Also, biochar decreases the bioavailability, toxicity and mobility of organic and inorganic 


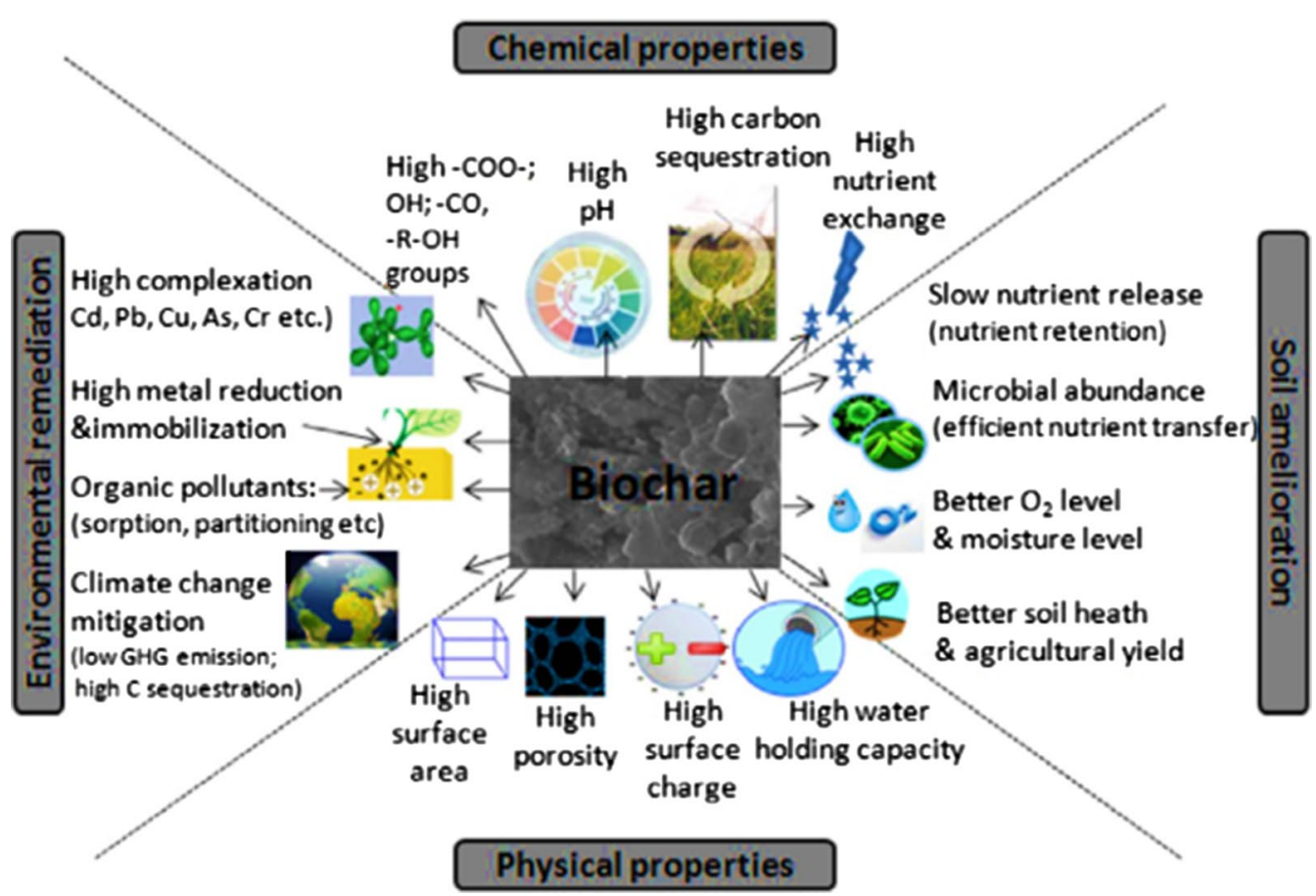

Fig. 7 Biochar characteristics and suitability for specific applications (adapted from Oliveira et al. 2017)

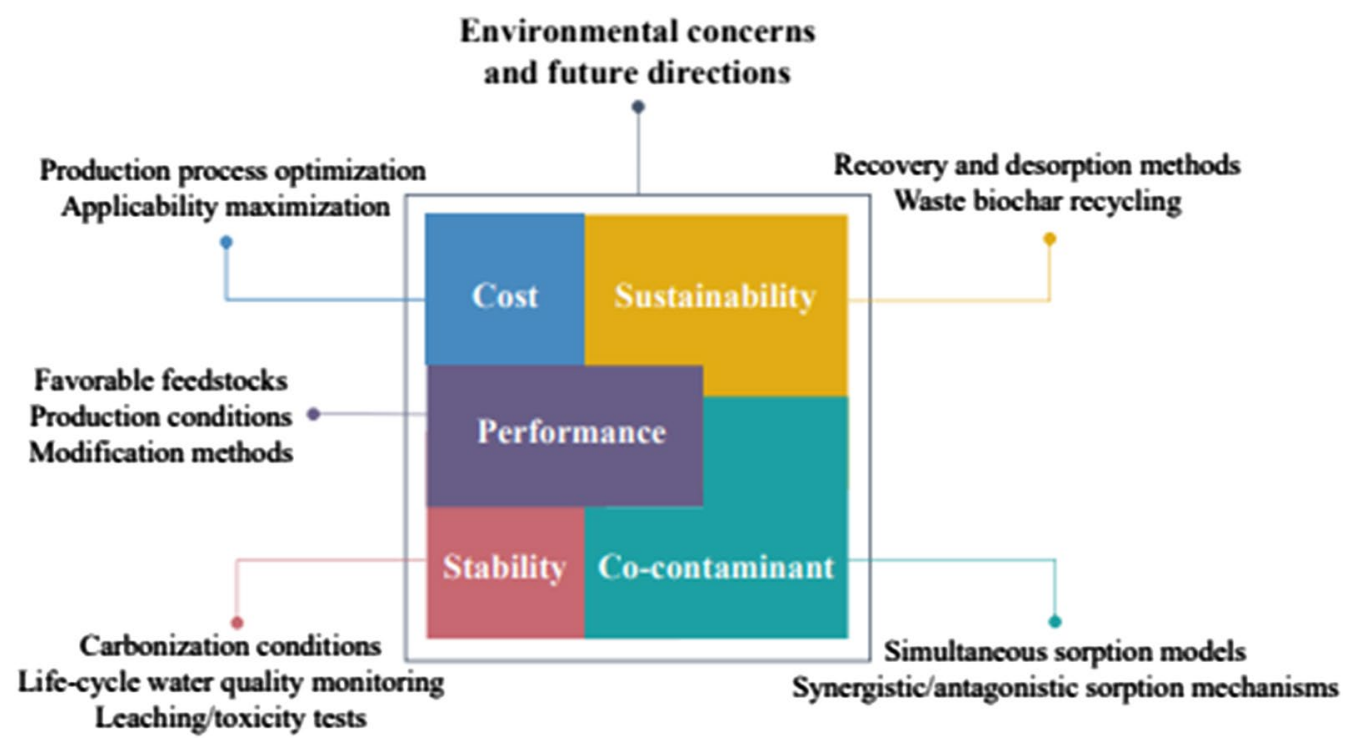

Fig. 8 Future proposed research mechanism for biochar application

pollutants and reported to be beneficial for the removal of contaminants at high concentrations. This review suggests that biochar might be used as an effective, low-cost and environmentally friendly adsorbent for the removal of organic and inorganic pollutants removal in industrial wastewater.

Acknowledgments This study was supported by the Netherlands Fellowship Programmes (NFP) for capacity building. S.R. thanks EPFL.
Funding Open Access funding provided by EPFL Lausanne.

\section{Compliance with ethical standards}

Conflict of interest The authors declare that they have no conflict of interest arising from this work.

Open Access This article is licensed under a Creative Commons Attribution 4.0 International License, which permits use, sharing, 
adaptation, distribution and reproduction in any medium or format, as long as you give appropriate credit to the original author(s) and the source, provide a link to the Creative Commons licence, and indicate if changes were made. The images or other third party material in this article are included in the article's Creative Commons licence, unless indicated otherwise in a credit line to the material. If material is not included in the article's Creative Commons licence and your intended use is not permitted by statutory regulation or exceeds the permitted use, you will need to obtain permission directly from the copyright holder. To view a copy of this licence, visit http://creativecommons .org/licenses/by/4.0/.

\section{References}

Agrafioti E, Kalderis D, Diamadopoulos E (2014) Arsenic and chromium removal from water using biochars derived from rice husk, organic solid wastes and sewage sludge. J Environ Manage 133:309-314

Ahmad Z, Gao B (2018) Use of fruit and vegetable waste-based biochar for removal of heavy metals from aqueous solution. Inter $\mathbf{J}$ AgricBiosyst Eng 12:1-9

Ahmad M, Lee SS, Dou X, Mohan D, Sung JK, Yang JE, Ok YS (2012) Effects of pyrolysis temperature on soybean stover-and peanut shell-derived biochar properties and TCE adsorption in water. Bioresour Technol 118:536-544. https://doi.org/10.1016/j.biort ech.2012.05.042

Ahmad M, Rajapaksha AU, Lim JE, Zhang M, Bolan N, Mohan D, Vithanage M, Lee SS, Ok YS (2014) Biochar as a sorbent for contaminant management in soil and water: a review. Chemosphere 99:19-33. https://doi.org/10.1016/j.chemospher e.2013.10.071

Ahmed MB, Zhou JL, Ngo HH, Guo W, Chen M (2016) Progress in the preparation and application of modified biochar for improved contaminant removal from water and wastewater. Bioresour Technol 214:836-851. https://doi.org/10.1016/j.biort ech.2016.05.057

Ahmed MB, Zhou JL, Ngo HH, Johir MAH, Sornalingam K (2018) Sportive removal of phenolic endocrine disruptors by functionalized biochar: competitive interaction mechanism, removal efficacy, and application in wastewater. Chem Eng J 335:801-811. https://doi.org/10.1016/j.cej.2017.11.041

Ambaye TG, Vaccari M, Castro FD, Prasad S, Rtimi S (2020) Emerging technologies for the recovery of rare earth elements (REEs) from the end-of-life electronic wastes: a review on progress, challenges, and perspectives. Environ Sci Poll Res 27(29):3605236074. https://doi.org/10.1007/s11356-020-09630-2

Atkinson CJ, Fitzgerald JD, Hipps NA (2010) Potential mechanisms for achieving agricultural benefits from biochar application to temperate soils: a review. Plant Soil 337:1-18. https://doi. org/10.1007/s11104-010-0464-5

Aydın YA, Aksoy ND (2009) Adsorption of chromium on chitosan: optimization, kinetics, and thermodynamics. Chem Eng J 151:188-194. https://doi.org/10.1016/j.cej.2009.02.010

Bartoli M, Rosi L, Giovannelli A, Frediani P, Frediani M (2016) Production of bio-oils and bio-char from Arundo donax through microwave-assisted pyrolysis in a multimode batch reactor. $\mathbf{J}$ Anal Appl Pyrolysis 122:479-489. https://doi.org/10.1016/j. jaap.2016.10.016

Bhatnagar A, Jain AK (2005) A comparative adsorption study with different industrial wastes as adsorbents for the removal of cationic dyes from water. J. Colloid Interface Sci 281(1):49-55

Bielská L, Škulcová L, Neuwirthová N, Cornelissen G, Hale SE (2018) Sorption, bioavailability and ecotoxic effects of hydrophobic organic compounds in biochar amended soils. Sci Total Environ 624:78-86. https://doi.org/10.1016/j.scitotenv.2017.12.098

Boutsika LG, Karapanagioti HK, Manariotis ID (2014) Aqueous mercury sorption by biochar from malt spent rootlets. Water Air Soil Pollut 225:1805. https://doi.org/10.1007/s11270-013-1805-9

Cao X, Harris W (2010) Properties of dairy-manure-derived biochar pertinent to its potential use in remediation. Bioresour Technol 101:5222-5228. https://doi.org/10.1016/j.biortech.2010.02.052

Cao X, Ma L, Gao B, Harris W (2009) Dairy-manure derived biochar effectively sorbs lead and atrazine. Environ Sci Technol 43:3285-3291. https://doi.org/10.1021/es803092k

Chen X, Chen G, Chen L, Chen Y, Lehmann J, McBride MB, Hay AG (2011b) Adsorption of copper and zinc by biochars produced from pyrolysis of hardwood and corn straw in aqueous solution. Bioresour Technol 102:8877-8884. https://doi. org/10.1016/j.biortech.2011.06.078

Chen B, Chen Z (2009) Sorption of naphthalene and 1-naphthol by biochars of orange peels with different pyrolytic temperatures. Chemosphere 76:127-133. https://doi.org/10.1016/j.chemo sphere.2009.02.004

Chen B, Chen Z, Lv S (2011a) Novel magnetic biochar efficiently sorbs organic pollutants and phosphate. Bioresour Technol 102:716-723. https://doi.org/10.1016/j.biortech.2010.08.067

Chen Z, Chen B, Zhou D, Chen W (2012) Bisolute sorption and thermodynamic behavior of organic pollutants to biomass-derived biochars at two pyrolytic temperatures. Environ Sci Technol 46:12476-12483. https://doi.org/10.1021/es303351e

Chen Z, Xiao X, Chen B, Zhu L (2014) Quantification of chemical states, dissociation constants, and contents of oxygen-containing groups on the surface of biochars produced at different temperatures. Environ Sci Technol 49:309-317. https://doi. org/10.1021/es5043468

Colmenares JC, Lisowski P, Łomot D (2013) A novel biomass-based support (Starbon) for $\mathrm{TiO}_{2}$ hybrid photocatalysts: a versatile green tool for water purification. RSC Adv 3:20186-20192. https://doi.org/10.1039/C3RA43673J

Colmenares JC, Varma RS, Lisowski P (2016) Sustainable hybrid photocatalysts: titania immobilized on carbon materials derived from renewable and biodegradable resources. Green Chem 18:5736-5750. https://doi.org/10.1039/C6GC02477G

Cuong DV, Liu NL, Nguyen VA, Hou CH (2019) Meso/microporecontrolled hierarchical porous carbon derived from activated biochar as a high-performance adsorbent for copper removal. Sci Total Environ 692:844-853. https://doi.org/10.1016/j.scito tenv.2019.07.125

Dai Y, Zhang N, Xing C, Cui Q, Sun Q (2019) The adsorption, regeneration and engineering applications of biochar for removal organic pollutants: a review. Chemosphere 223:12-27. https:// doi.org/10.1016/j.chemosphere.2019.01.161

De Ridder M, De Jong S, Polchar J, Lingemann S (2012) Risks and opportunities in the global phosphate rock market: robust strategies in times of uncertainty. Hague Centre for Strategic Studies. https://library.wur.nl/WebQuery/titel/2016340

Dong X, Ma LQ, Li Y (2011) Characteristics and mechanisms of hexavalent chromium removal by biochar from sugar beet tailing. J Hazard Mater 190:909-915. https://doi.org/10.1016/j.jhazm at.2011.04.008

Downie A, Crosky A, Munroe P (2009) Physical properties of biochar. Biochar for environmental management. Sci Technol 13-32. http://www.css.cornell.edu/faculty/lehmann/publ/First\%20pro of\%2013-01-09.pdf

El-Shafey EI (2010) Removal of $\mathrm{Zn}$ (II) and $\mathrm{Hg}$ (II) from aqueous solution on a carbonaceous sorbent chemically prepared from rice husk. J Hazard Mater 175:319-327. https://doi.org/10.1016/j. jhazmat.2009.10.006 
Fagbohungbe MO, Herbert BM, Hurst L, Ibeto CN, Li H, Usmani SQ, Semple KT (2017) The challenges of anaerobic digestion and the role of biochar in optimizing anaerobic digestion. Waste Manag 61:236-249. https://doi.org/10.1016/j.wasman.2016.11.028

Fan S, Wang Y, Wang Z, Tang J, Tang J, Li X (2017) Removal of methylene blue from aqueous solution by sewage sludge-derived biochar: adsorption kinetics, equilibrium, thermodynamics, and mechanism. J Environ Chem Eng 5:601-611. https://doi. org/10.1016/j.jece.2016.12.019

Fu H, Wei C, Qu X, Li H, Zhu D (2018) Strong binding of apolar hydrophobic organic contaminants by dissolved black carbon released from biochar: a mechanism of pseudomicelle partition and environmental implications. Environ Pollut 232:402-410. https://doi.org/10.1016/j.envpol.2017.09.053

Fuertes AB, Arbestain MC, Sevilla M, Maciá-Agulló JA, Fiol S, López R, Smernik RJ, Aitkenhead WP, Arce F, Macìas F (2010) Chemical and structural properties of carbonaceous products obtained by pyrolysis and hydrothermal carbonization of corn stover. Soil Res 48:618-626. https://doi.org/10.1071/SR10010

Giannakis S, Rtimi S, Pulgarin C (2017) Light-assisted advanced oxidation processes for the elimination of chemical and microbiological pollution of wastewaters in developed and developing countries. Molecules 22:1070. https://doi.org/10.3390/molec ules22071070

Goh KH, Lim TT, Dong Z (2008) Application of layered double hydroxides for removal of oxyanions: a review. Water Res 42:1343-1368. https://doi.org/10.1016/j.watres.2007.10.043

Hairuddin MN, Mubarak NM, Khalid M, Abdullah EC, Walvekar R, Karri RR (2019) Magnetic palm kernel biochar potential route for phenol removal from wastewater. Environ Sci Pollut Res 26(34):35183-35197

Hale SE, Lehmann J, Rutherford D, Zimmerman AR, Bachmann RT, Shitumbanuma V, O'Toole A, Sundqvist KL, Arp HP, Cornelissen G (2012) Quantifying the total and bioavailable polycyclic aromatic hydrocarbons and dioxins in biochars. Environ Sci Technol 46:2830-2838. https://doi.org/10.1021/es203984k

Han X, Chu L, Liu S, Chen T, Ding C, Yan J, Cui L, Quan G (2015) Removal of methylene blue from aqueous solution using porous biochar obtained by $\mathrm{KOH}$ activation of peanut shell biochar. Bio Resour 10:2836-2849

He R, Peng Z, Lyu H, Huang H, Nan Q, Tang J (2018) Synthesis and characterization of iron-impregnated biochar for aqueous arsenic removal. Sci Total Environ 612:1177-1186. https://doi. org/10.1016/j.scitotenv.2017.09.016

Hossain MK, Strezov V, Chan KY, Ziolkowski A, Nelson PF (2011) Influence of pyrolysis temperature on the production and nutrient properties of wastewater sludge biochar. J Environ Manag 92:223-228. https://doi.org/10.1016/j.jenvman.2010.09.008

Igalavithana AD, Mandal S, Niazi NK, Vithanage M, Parikh SJ, Mukome FN, Rizwan M, Oleszczuk P, Al-Wabel M, Bolan N, Tsang DC (2017) Advances and future directions of biochar characterization methods and applications. Crit Rev Environ Sci Technol 47(23):2275-2330

Inyang M, Gao B, Ding W, Pullammanappallil P, Zimmerman AR, Cao X (2011) Enhanced lead sorption by biochar derived from anaerobically digested sugarcane bagasse. Sep Sci Technol 46:1950-1956. https://doi.org/10.1080/01496395.2011.584604

Inyang M, Gao B, Yao Y, Xue Y, Zimmerman AR, Pullammanappallil P, Cao X (2012) Removal of heavy metals from aqueous solution by biochars derived from anaerobically digested biomass. Bioresour Technol 110:50-56. https://doi.org/10.1016/j.biort ech.2012.01.072

Inyang M, Gao B, Zimmerman A, Zhang M, Chen H (2014) Synthesis, characterization, and dye sorption ability of carbon nanotubebiochar nanocomposites. Chem Eng J 236:39-46. https://doi. org/10.1016/j.cej.2013.09.074
Inyang MI, Gao B, Yao Y, Xue Y, Zimmerman A, Mosa A, Pullammanappallil P, Ok YS, Cao X (2016) A review of biochar as a low-cost adsorbent for aqueous heavy metal removal. Crit Rev Environ Sci Technol 46:406-433. https://doi.org/10.1080/10643 389.2015.1096880

Jia M, Wang F, Bian Y, Jin X, Song Y, Kengara FO, Xu R, Jiang X (2013) Effects of $\mathrm{pH}$ and metal ions on oxytetracycline sorption to maize-straw-derived biochar. Bioresour Technol 136:87-93. https://doi.org/10.1016/j.biortech.2013.02.098

Joseph SD, Camps-Arbestain M, Lin Y, Munroe P, Chia CH, Hook J, Van Zwieten L, Kimber S, Cowie A, Singh BP, Lehmann J (2010) An investigation into the reactions of biochar in soil. Soil Res 48:501-515. https://doi.org/10.1071/SR10009

Jung C, Park J, Lim KH, Park S, Heo J, Her N, Oh J, Yun S, Yoon Y (2013) Adsorption of selected endocrine disrupting compounds and pharmaceuticals on activated biochars. J Hazard Mater 263:702-710. https://doi.org/10.1016/j.jhazmat.2013.10.033

Kah M, Sigmund G, Xiao F, Hofmann T (2017) Sorption of ionizable and ionic organic compounds to biochar activated carbon and other carbonaceous materials. Water Res 124:673-692. https:// doi.org/10.1016/j.watres.2017.07.070

Kalaivani GJ, Suja SK (2016) $\mathrm{TiO}_{2}$ (rutile) embedded inulin-a versatile bio-nano composite for photocatalytic degradation of methylene blue. Carbohydr Polym 143:51-60. https://doi.org/10.1016/j. carbpol.2016.01.054

Kalderis D, Kayan B, Akay S, Kulaksız E, Gözmen B (2017) Adsorption of 2,4-dichlorophenol on paper sludge/wheat husk biochar: process optimization and comparison with biochars prepared from woodchips, sewage sludge and hog fuel/demolition waste. J Environ Chem Eng 5:2222-2231. https://doi.org/10.1016/j. jece.2017.04.039

Karakoyun N, Kubilay S, Aktas N, Turhan O, Kasimoglu M, Yilmaz S, Sahiner N (2011) Hydrogel-biochar composites for effective organic contaminant removal from aqueous media. Desalination 280:319-325. https://doi.org/10.1016/j.desal.2011.07.014

Kasozi GN, Zimmerman AR, Nkedi-Kizza P, Gao B (2010) Catechol and humic acid sorption onto a range of laboratory-produced black carbons (biochars). Environ Sci Technol 44(16):61896195. https://doi.org/10.1021/es1014423

Keiluweit M, Nico PS, Johnson MG, Kleber M (2010) Dynamic molecular structure of plant biomass-derived black carbon (biochar). Environ Sci Technol 44:1247-1253. https://doi.org/10.1021/ es9031419

Khataee A, Kayan B, Gholami P, Kalderis D, Akay S (2017a) Sonocatalytic degradation of an anthraquinone dye using $\mathrm{TiO}_{2}$-biochar nanocomposite. Ultrason Sonochem 39:120-128. https://doi. org/10.1016/j.ultsonch.2017.04.018

Khataee A, Kayan B, Gholami P, Kalderis D, Akay S, Dinpazhoh L (2017b) Sonocatalytic degradation of reactive yellow 39 using synthesized $\mathrm{ZrO}_{2}$ nanoparticles on biochar. Ultrason Sonochem 39:540-549. https://doi.org/10.1016/j.ultsonch.2017.05.023

Kim J, Hyun S (2018) Sorption of ionic and nonionic organic solutes onto giant Miscanthus-derived biochar from methanolwater mixtures. Sci Total Environ 615:805-813. https://doi. org/10.1016/j.scitotenv.2017.09.296

Kim JR, Kan E (2016) Heterogeneous photocatalytic degradation of sulfamethoxazole in water using a biochar-supported $\mathrm{TiO}_{2}$ photocatalyst. J Environ Manag 180:94-101. https://doi.org/10.1016/j. jenvman.2016.05.016

Kim KH, Kim JY, Cho TS, Choi JW (2012) Influence of pyrolysis temperature on the physicochemical properties of biochar obtained from the fast pyrolysis of pitch pine (Pinus rigida). Bioresour Technol 118:158-162. https://doi.org/10.1016/j.biort ech.2012.04.094

Klasson KT, Ledbetter CA, Uchimiya M, Lima IM (2013) Activated biochar removes $100 \%$ dibromochloropropane from field well 
water. Environ Chem Lett 11:271-275. https://doi.org/10.1007/ s10311-012-0398-7

Kołodyńska D, Wnętrzak R, Leahy JJ, Hayes MH, Kwapiński W, Hubicki ZJ (2012) Kinetic and adsorptive characterization of biochar in metal ions removal. Chem Eng J 197:295-305. https ://doi.org/10.1016/j.cej.2012.05.025

Kong H, He J, Gao Y, Wu H, Zhu X (2011) Co sorption of phenanthrene and mercury (II) from aqueous solution by soybean stalkbased biochar. J Agric Food Chem 59:12116-12123. https://doi. org/10.1021/jf202924a

Kumar A, Kumar A, Sharma G, Naushad M, Stadler FJ, Ghfar AA, Dhiman P, Saini RV (2017) Sustainable nano-hybrids of magnetic biochar supported g-C $3 \mathrm{~N} 4 / \mathrm{FeVO}_{4}$ for solar-powered degradation of noxious pollutants-Synergism of adsorption, photocatalysis and photo-ozonation. J Clean Prod 165:431-451. https ://doi.org/10.1016/j.jclepro.2017.07.117

Lalhruaitluanga H, Jayaram K, Prasad MNV, Kumar KK (2010) Lead (II) adsorption from aqueous solutions by raw and activated charcoals of Melocanna baccifera Roxburgh (bamboo) - a comparative study. J Hazard Mater 175(1-3):311-318

Lam YF, Lee LY, Chua SJ, Lim SS, Gan S (2016) Insights into the equilibrium, kinetic and thermodynamics of nickel removal by environmentally friendly Lansium domesticum peel biosorbent. Ecotoxicol Environ Saf 127:61-70. https://doi.org/10.1016/j. ecoenv.2016.01.003

Li M, Huang H, Yu S, Tian N, Dong F, Du X, Zhang Y (2016) Simultaneously promoting charge separation and photoabsorption of $\mathrm{BiO}_{X}(X=\mathrm{Cl}, \mathrm{Br})$ for efficient visible-light photocatalysis and photosensitization by compositing low-cost biochar. Appl Surf Sci 386:285-295. https://doi.org/10.1016/j.apsusc.2016.05.171

Li H, Cao Y, Zhang D, Pan B (2018) pH-dependent KOW provides new insights into understanding the adsorption mechanism of ionizable organic chemicals on carbonaceous materials. Sci Total Environ 618:269-275. https://doi.org/10.1016/j.scitotenv.2017.11.065

Lima EC (2018) Removal of emerging contaminants from the environment by adsorption. Ecotoxicol Environ Saf 150:1-17. https:// doi.org/10.1016/j.ecoenv.2017.12.026

Lisowski P, Colmenares JC, Mašek O, Lisowski W, Lisovytskiy D, Kamińska A, Łomot D (2017) Dual functionality of $\mathrm{TiO}_{2} /$ biochar hybrid materials: photocatalytic phenol degradation in the liquid phase and selective oxidation of methanol in the gas phase. ACS Sustain Chem Eng 5:6274-6287. https://doi.org/10.1021/acssu schemeng.7b01251

Liu Z, Zhang FS (2009) Removal of lead from water using biochars prepared from hydrothermal liquefaction of biomass. J Hazard Mater 167:933-939. https://doi.org/10.1016/j.jhazm at.2009.01.085

Liu Z, Zhang FS, Wu J (2010) Characterization and application of chars produced from pinewood pyrolysis and hydrothermal treatment. Fuel 89:510-514. https://doi.org/10.1016/j.fuel.2009.08.042

Liu Y, Yang M, Wu Y, Wang H, Chen Y, Wu W (2011) Reducing $\mathrm{CH}_{4}$ and $\mathrm{CO}_{2}$ emissions from waterlogged paddy soil with biochar. J Soils Sediments 11:930-939. https://doi.org/10.1007/ s11368-011-0376-x

Liu WJ, Jiang H, Yu HQ (2015) Development of biochar-based functional materials: toward a sustainable platform carbon material. Chem Rev 115:12251-12285. https://doi.org/10.1021/acs. chemrev.5b00195

Liu QY, Yang F, Sun XF, Liu ZH, Li G (2017) Preparation of biochar catalysts with saccharide and lignocellulose residues of corncob degradation for corncob hydrolysis into furfural. J Mater Cycles Waste Manag 19:134-143. https://doi.org/10.1007/ s10163-015-0392-9

Lou W, Kane A, Wolbert D, Rtimi S, Assadi AA (2017) Study of a photocatalytic process for removal of antibiotics from wastewater in a falling film photoreactor: Scavenger study and process intensification feasibility. Chem Eng Proc Proc Intensif 122:213-221. https://doi.org/10.1016/j.cep.2017.10.010

Lu H, Zhang W, Yang Y, Huang X, Wang S, Qiu R (2012) Relative distribution of $\mathrm{Pb}^{2+}$ sorption mechanisms by sludge-derived biochar. Water Res 46:854-862. https://doi.org/10.1016/j.watre s.2011.11.058

Lu K, Yang X, Gielen G, Bolan N, Ok YS, Niazi NK, Xu S, Yuan G, Chen X, Zhang X, Liu D (2017) Effect of bamboo and rice straw biochars on the mobility and redistribution of heavy metals $(\mathrm{Cd}, \mathrm{Cu}, \mathrm{Pb}$ and $\mathrm{Zn})$ in contaminated soil. J Environ Manage 186:285-292

Ludwig RD, Su Ch, Lee TR, Wilkin RT, Acree SD, Ross RR, Keeley A (2007) In situ chemical reduction of $\mathrm{Cr}(\mathrm{VI})$ in groundwater using a combination of ferrous sulfate and sodium dithionite: a field investigation. Environ Sci Technol 41(15):5299-5305. https://doi.org/10.1021/es070025z

Luo L, Yang Y, Xiao M, Bian L, Yuan B, Liu Y, Jiang F, Pan X (2015) A novel biotemplated synthesis of $\mathrm{TiO}_{2}$ /wood charcoal composites for synergistic removal of bisphenol A by adsorption and photocatalytic degradation. Chem Eng J 262:12751283. https://doi.org/10.1016/j.cej.2014.10.087

Matos J (2016) Eco-friendly heterogeneous photocatalysis on biochar-based materials under solar irradiation. Top Catal 59:394402. https://doi.org/10.1007/s11244-015-0434-5

Matos J, Atienzar P, García H, Hernández-Garrido JC (2013a) Nanocrystalline carbon- $\mathrm{TiO}_{2}$ hybrid hollow spheres as possible electrodes for solar cells. Carbon 53:169-181. https:// doi.org/10.1016/j.carbon.2012.10.044

Matos J, Hofman M, Pietrzak R (2013b) Synergy effect in the photocatalytic degradation of methylene blue on a suspended mixture of $\mathrm{TiO}_{2}$ and N-containing carbons. Carbon 54:460-471. https://doi.org/10.1016/j.carbon.2012.12.002

Medyńska-Juraszek A, Rivier P-A, Rasse D, Joner EJ (2020) Biochar affects heavy metal uptake in plants through interactions in the Rhizosphere. Appl Sci 10:5105. https://doi.org/10.3390/ app 10155105

Mohan D, Pittman CU Jr (2007) Arsenic removal from water/wastewater using adsorbents-a critical review. J Hazard Mater 142:1-53. https://doi.org/10.1016/j.jhazmat.2007.01.006

Mohan D, Rajput S, Singh VK, Steele PH, Pittman CU Jr (2011) Modeling and evaluation of chromium remediation from water using low-cost bio-char, a green adsorbent. J Hazard Mater 188:319-333. https://doi.org/10.1016/j.jhazmat.2011.01.127

Mohan D, Sarswat A, Ok YS, Pittman CU Jr (2014) Organic and inorganic contaminants removal from water with biochar, a renewable, low cost and sustainable adsorbent-a critical review. Bioresour Technol 160:191-202. https://doi. org/10.1016/j.biortech.2014.01.120

Moreno-Castilla C (2004) Adsorption of organic molecules from aqueous solutions on carbon materials. Carbon 42:83-94. https ://doi.org/10.1016/j.carbon.2003.09.022

Mu'azu ND, Jarrah N, Zubair M, Alagha O, (2017) Removal of phenolic compounds from water using sewage sludge-based activated carbon adsorption: a review. Int J Environ Res Public Health 14:1094. https://doi.org/10.3390/ijerph14101094

Mubarak NM, Alicia RF, Abdullah EC, Sahu JN, Haslija AA, Tan J (2013a) Statistical optimization and kinetic studies on the removal of $\mathrm{Zn}^{2+}$ using functionalized carbon nanotubes and magnetic biochar. J Environ Chem Eng 1:486-495

Mubarak NM, Ruthiraan M, Sahu JN, Abdullah EC, Jayakumar NS, Sajuni NR, Tan J (2013b) Adsorption and kinetic study on $\mathrm{Sn}^{2+}$ removal using modified carbon nanotube and magnetic biochar. Int J Nanosci 12:1350044. https://doi.org/10.1142/ S0219581X13500440

Mubarak NM, Sahu JN, Abdullah EC, Jayakumar NS (2016) Plam oil empty fruit bunch based magnetic biochar composite comparison 
for synthesis by microwave-assisted and conventional heating. J Analy Appl Pyrol 120:521-528

Mukherjee A, Zimmerman AR (2013) Organic carbon and nutrient release from a range of laboratory-produced biochars and biochar-soil mixtures. Geoderma 193:122-130. https://doi. org/10.1016/j.geoderma.2012.10.002

Mukherjee A, Zimmerman AR, Harris W (2011) Surface chemistry variations among a series of laboratory-produced biochars. Geoderma 163:247-255. https://doi.org/10.1016/j.geode rma.2011.04.021

Novak JM, Lima I, Xing B, Gaskin JW, Steiner C, Das KC, Ahmedna M, Rehrah D, Watts DW, Busscher WJ, Schomberg H (2009) Characterization of designer biochar produced at different temperatures and their effects on loamy sand. Ann Environ Sci 3:195-206

O'Connor D, Peng T, Zhang J, Tsang DCW, Alessi DS, Shen Z, Bolan NS, Hou D (2018) Biochar application for the remediation of heavy metal polluted land: a review of in situ field trials. Sci Total Environ 619-620:815-826. https://doi.org/10.1016/j. scitotenv.2017.11.132

Oliveira FR, Patel AK, Jaisi DP, Adhikari S, Lu H, Khanal SK (2017) Environmental application of biochar: current status and perspectives. Bioresour Technol 246:110-122. https://doi. org/10.1016/j.biortech.2017.08.122

Özçimen D, Karaosmanoğlu F (2004) Production and characterization of bio-oil and biochar from rapeseed cake. Renew Energy 29:779-787. https://doi.org/10.1016/j.renene.2003.09.006

Park JH, Choppala GK, Bolan NS, Chung JW, Chuasavathi T (2011) Biochar reduces the bioavailability and phytotoxicity of heavy metals. Plant Soil 348:439. https://doi.org/10.1007/s1110 4-011-0948-y

Park JH, Ok YS, Kim SH, Cho JS, Heo JS, Delaune RD, Seo DC (2016) Competitive adsorption of heavy metals onto sesame straw biochar in aqueous solutions. Chemosphere 142:77-83. https://doi.org/10.1016/j.chemosphere.2015.05.093

Parmar KR, Ross AB (2019) Integration of hydrothermal carbonisation with anaerobic digestion: Opportunities for valorisation of digestate. Energies 12:1586. https://doi.org/10.3390/en120 91586

Parshetti GK, Hoekman SK, Balasubramanian R (2013) Chemical, structural and combustion characteristics of carbonaceous products obtained by hydrothermal carbonization of palm empty fruit bunches. Bioresour Technol 135:683-689

Peiris C, Gunatilak SR, Mlsna TE, Mohan D, Vithanage M (2017) Biochar based removal of antibiotic sulfonamides and tetracyclines in aquatic environments: a critical review. Bioresour Technol. https://doi.org/10.1016/j.biortech.2017.07.150

Pellera FM, Giannis A, Kalderis D, Anastasiadou K, Stegmann R, Wang JY, Gidarakos E (2012) Adsorption of $\mathrm{Cu}$ (II) ions from aqueous solutions on biochars prepared from agricultural byproducts. J Environ Manag 96:35-42. https://doi.org/10.1016/j. jenvman.2011.10.010

Peng XY, Ye LL, Wang CH, Zhou H, Sun B (2011) Temperature-and duration-dependent rice straw-derived biochar: Characteristics and its effects on soil properties of a Ultisol in southern China. Soil Tillage Res 112:159-166. https://doi.org/10.1016/j.still .2011 .01 .002

Pi L, Jiang R, Zhou W, Zhu H, Xiao W, Wang D, Mao X (2015) g- $\mathrm{C}_{3} \mathrm{~N}_{4}$ modified biochar as an adsorptive and photocatalytic material for the decontamination of aqueous organic pollutants. Appl Surf Sci 358:231-239. https://doi.org/10.1016/j.apsusc.2015.08.176

Puga AP, Abreu CA, Melo LCA, Beesley L (2016) Biochar application to a contaminated soil reduces the availability and plant uptake of zinc, lead and cadmium. J Environ Manag 159:86-93. https:// doi.org/10.1016/j.jenvman.2015.05.036
Qayyum MF, Liaqat F, Rehman RA, Gul M, Hye MZ, Rizwan M, Rehman MZ (2017) Effects of co-composting of farm manure and biochar on plant growth and carbon mineralization in an alkaline soil. Environ Sci Pollut Res 24:26060-26068. https:// doi.org/10.1007/s11356-017-0227-4

Qiao K, Tian W, Bai J, Dong J, Zhao J, Gong X, Liu S (2018) Preparation of biochar from enteromorpha prolifera and its use for the removal of polycyclic aromatic hydrocarbons (PAHs) from aqueous solution. Ecotoxicol Environ Saf 149:80-87. https://doi. org/10.1016/j.ecoenv.2017.11.027

Qiu Y, Zheng Z, Zhou Z, Sheng GD (2009) Effectiveness and mechanisms of dye adsorption on a straw-based biochar. Bioresour Technol 100:5348-5351. https://doi.org/10.1016/j.biort ech.2009.05.054

Rajapaksha AU, Vithanage M, Ahmad M, Seo DC, Cho JS, Lee SN, Lee SS, Ok YS (2015) Enhanced sulfamethazine removal by steam activated invasive plant-derived biochar. J Hazard Mater 290:43-50. https://doi.org/10.1016/j.jhazmat.2015.02.046

Reddy DH, Lee SM (2013) Application of magnetic chitosan composites for the removal of toxic metal and dyes from aqueous solutions. Adv Colloid Interface Sci 201:68-93. https://doi. org/10.1016/j.cis.2013.10.002

Rehman MZ, Khalid H, Akmal F, Ali S, Rizwan M, Qayyum MF, Iqbal M, Khalid MU, Azhar M (2017) Effect of limestone, lignite and biochar applied alone and combined on cadmium uptake in wheat and rice under rotation in an effluent irrigated the field. Environ Pollut 227:560-568. https://doi.org/10.1016/j.envpo 1.2017.05.003

Rizwan M, Ali S, Qayyum MF, Ibrahim M, Rehman MZ, Abbas T, Ok YS (2016) Mechanisms of biochar-mediated alleviation of toxicity of trace elements in plants: a critical review. Environ Sci Pollut Res 23:2230-2248. https://doi.org/10.1007/s1135 6-015-5697-7

Shang J, Zong M, Yu Y, Kong X, Du Q, Liao Q (2017) Removal of chromium (VI) from water using nanoscale zerovalent iron particles supported on herb-residue biochar. J Environ Manage 197:331-337

Sizmur T, Fresno T, Akgül G, Frost H, Moreno-Jiménez E (2017) Biochar modification to enhance sorption of inorganics from water. Bioresour Technol 246:34-47

Spokas KA (2010) Review of the stability of biochar in soils: predictability of O: C molar ratios. Carbon Manag 1:289-303. https:// doi.org/10.4155/cmt.10.32

Sun K, Ro K, Guo M, Novak J, Mashayekhi H, Xing B (2011) Sorption of bisphenol A, 17 $\alpha$-Ethinyl estradiol and phenanthrene on thermally and hydrothermally produced biochars. Bioresour Technol 102:5757-5763. https://doi.org/10.1016/j.biortech.2011.03.038

Sun K, Kang M, Zhang Z, Jin J, Wang Z, Pan Z, Xu D, Wu F, Xing B (2013a) Impact of deashing treatment on biochar structural properties and potential sorption mechanisms of phenanthrene. Environ Sci Technol 47:11473-11481. https://doi.org/10.1021/ es4026744

Sun L, Wan S, Luo W (2013b) Biochars prepared from anaerobic digestion residue, palm bark, and eucalyptus for adsorption of cationic methylene blue dye: characterization, equilibrium, and kinetic studies. Bioresour Technol 140:406-413. https://doi. org/10.1016/j.biortech.2013.04.116

Sun Y, Gao B, Yao Y, Fang J, Zhang M, Zhou Y, Chen H, Yang L (2014) Effects of feedstock type, production method, and pyrolysis temperature on biochar and hydrochar properties. Chem Eng J 240:574-578. https://doi.org/10.1016/j.cej.2013.10.081

Thies JE, Rillig MC (2009) Characteristics of biochar: biological properties. Biochar for environmental management. Sci Technol 8:5-105. https://doi.org/10.4324/9781849770552-13 
Tong XJ, Li JY, Yuan JH, Xu RK (2011) Adsorption of Cu (II) by biochars generated from three crop straws. Chem Eng J 172:828-834. https://doi.org/10.1016/j.cej.2011.06.069

Trakal L, Veselská V, Šafařík I, Vítková M, Č́íhalová S, Komárek M (2016) Lead and cadmium sorption mechanisms on magnetically modified biochars. Biores Technol 203:318-324. https://doi. org/10.1016/j.biortech.2015.12.056

Tsai WT, Chen HR (2013) Adsorption kinetics of herbicide paraquat in aqueous solution onto a low-cost adsorbent, swine-manurederived biochar. Int J Environ Sci Technol 10(6):1349-1356

Van Zwieten L, Kimber S, Morris S, Chan KY, Downie A, Rust J, Joseph S, Cowie A (2010) Effects of biochar from slow pyrolysis of papermill waste on agronomic performance and soil fertility. Plant Soil 327:235-246. https://doi.org/10.1007/s11104-009-0050-x

Villegas- Guzman P, Giannakis S, Rtimi S, Grandjean D, Bensimon M, de Alencastro F, Torres-Palma R, Pulgarin C (2017) A green solar photo-Fenton process for the elimination of bacteria and micropollutants in municipal wastewater treatment using mineral iron and natural organic acids. Appl Catal B Environ 219:538-549. https:// doi.org/10.1016/j.apcatb.2017.07.066

Vithanage M, Mayakaduwa S, Herath I, Ok YS, Mohan D (2016) Kinetics, thermodynamics and mechanistic studies of carbofuran removal using biochars from tea waste and rice husks. Chemosphere 150:781-789. https://doi.org/10.1016/j.chemosphere.2015.11.002

Vyavahare GD, Gaurav RG, Jadhav PP, Patil RR, Aware CB, Jadhav JP (2018) Response surface methodology optimization for sorption of malachite green dye on sugarcane bagasse biochar and evaluating the residual dye for photo and cytogenotoxicity. Chemosphere 194:306-315. https://doi.org/10.1016/j.chemosphere.2017.11.180

Wang H, Yuan X, Zeng G, Leng L, Peng X, Liao K, Peng L, Xiao Z (2014) Removal of malachite green dye from wastewater by different organic acid-modified natural adsorbent: kinetics, equilibriums, mechanisms, practical application, and disposal of the dye-loaded adsorbent. Environ Sci Pollut Res 21:11552-11564. https://doi. org/10.1007/s11356-014-3025-2

Wang S, Gao B, Zimmerman AR, Li Y, Ma L, Harris WG, Migliaccio KW (2015) Removal of arsenic by magnetic biochar prepared from pinewood and natural hematite. Bioresour Technol 175:391-395. https://doi.org/10.1016/j.biortech.2014.10.104

Wang P, Liu X, Wu X, Xu J, Dong F, Zheng Y (2018) Evaluation of biochars in reducing the bioavailability of flubendiamide in water/sediment using passive sampling with polyoxymethylene. J Hazard Mater 344:1000-1006. https://doi.org/10.1016/j.jhazm at.2017.12.003

Wei D, Ngo HH, Guo W, Xu W, Du B, Khan MS, Wei Q (2018) Biosorption performance evaluation of heavy metal onto aerobic granular sludge-derived biochar in the presence of effluent organic matter via batch and fluorescence approaches. Bioresour Technol 249:410-416. https://doi.org/10.1016/j.biortech.2017.10.015

Weldon S, Rasse DP, Budai A, Tomic O, Dörsch P (2019) The effect of a biochar temperature series on denitrification: which biochar properties matter? Soil Bio Biochem 135:173-183. https://doi. org/10.1016/j.soilbio.2019.04.018

Wu F, Liu W, Qiu J, Li J, Zhou W, Fang Y, Zhang S, Li X (2015) Enhanced photocatalytic degradation and adsorption of methylene blue via $\mathrm{TiO}_{2}$ nanocrystals supported on graphene-like bamboo charcoal. Appl Surf Sci 358:425-435. https://doi.org/10.1016/j. apsusc.2015.08.161

Xia Y, Larock RC (2010) Vegetable oil-based polymeric materials: synthesis, properties, and applications. Green Chem 12:1893-1909. https://doi.org/10.1039/C0GC00264J

Xu RK, Xiao SC, Yuan JH, Zhao AZ (2011) Adsorption of methyl violet from aqueous solutions by the biochars derived from crop residues.
Bioresour Technol 102:10293-10298. https://doi.org/10.1016/j. biortech.2011.08.089

Xu X, Cao X, Zhao L, Wang H, Yu H, Gao B (2013) Removal of Cu, Zn, and $\mathrm{Cd}$ from aqueous solutions by the dairy manure-derived biochar. Environ Sci Pollut Res 20:358-368. https://doi.org/10.1007/ s11356-012-0873-5

Yang X, Chen Z, Wu Q, Xu M (2018) Enhanced phenanthrene degradation in river sediments using a combination of biochar and nitrate. Sci Total Environ 619-620:600-605. https://doi.org/10.1016/j.scito tenv.2017.11.130

Yao Y, Gao B, Inyang M, Zimmerman AR, Cao X, Pullammanappallil P, Yang L (2011a) Biochar derived from anaerobically digested sugar beet tailings: characterization and phosphate removal potential. Bioresour Technol 102:6273-6278. https://doi.org/10.1016/j. biortech.2011.03.006

Yao Y, Gao B, Inyang M, Zimmerman AR, Cao X, Pullammanappallil P, Yang L (2011b) Removal of phosphate from aqueous solution by biochar derived from anaerobically digested sugar beet tailings. J Hazard Mater 190:501-507. https://doi.org/10.1016/j.jhazm at.2011.03.083

Yao H, Lu J, Wu J, Lu Z, Wilson PC, Shen Y (2013a) Adsorption of fluoroquinolone antibiotics by wastewater sludge biochar: role of the sludge source. Water Air Soil Pollut 224:1370. https://doi. org/10.1007/s11270-012-1370-7

Yao Y, Gao B, Chen J, Yang L (2013b) Engineered biochar reclaiming phosphate from aqueous solutions: mechanisms and potential application as a slow-release fertilizer. Environ Sci Technol 47:8700-8708. https://doi.org/10.1021/es4012977

Younis U, Malik SA, Rizwan M, Qayyum MF, Ok YS, Shah MHR, Rehman RA, Ahmad N (2016) Biochar enhances the cadmium tolerance in spinach (Spinacia oleracea) through modification of Cd uptake and physiological and biochemical attributes. Environ Sci Poll Res 23:21385-21394. https://doi.org/10.1007/s1135 6-016-7344-3

X Zhang H Wang L He K Lu A Sarmah J Li NS Bolan J Pei H Huang (2013a) Using biochar for remediation of soils contaminated with heavy metals and organic pollutants Environ Sci Pollut Res 20:8472-8483 https://doi.org/10.1007/s11356-013-1659-0

Zhang W, Mao S, Chen H, Huang L, Qiu R (2013b) Pb (II) and Cr (VI) sorption by biochars pyrolyzed from the municipal wastewater sludge under different heating conditions. Bioresour Technol 147:545-552. https://doi.org/10.1016/j.biortech.2013.08.082

Zhang H, Wang Z, Li R, Guo J, Li Y, Zhu J, Xie X (2017) $\mathrm{TiO}_{2}$ supported on reed straw biochar as an adsorptive and photocatalytic composite for the efficient degradation of sulfamethoxazole in aqueous matrices. Chemosphere 185:351-360. https://doi.org/10.1016/j. chemosphere.2017.07.025

Zhang Y, Cao B, Zhao L, Sun L, Gao Y, Li J, Yang F (2018) Biocharsupported reduced graphene oxide composite for adsorption and coadsorption of atrazine and lead ions. Appl Surf Sci 427:147-155. https://doi.org/10.1016/j.apsusc.2017.07.237

Zhao N, Yang X, Zhang J, Zhu L, Lv Y (2017) Adsorption mechanisms of dodecylbenzene sulfonic acid by corn straw and poplar leaf biochars. Materials 10:1119. https://doi.org/10.3390/ma10101119

Zheng H, Wang Z, Zhao J et al (2013) Sorption of antibiotic sulfamethoxazole varies with biochars produced at different temperatures. Environ Pollut 181:60-67. https://doi.org/10.1016/j.envpol.2013.05.056

Zhou Y, Gao B, Zimmerman AR, Chen H, Zhang M, Cao X (2014) Biochar-supported zerovalent iron for removal of various contaminants from aqueous solutions. Bioresour Technol 152:538-542. https:// doi.org/10.1016/j.biortech.2013.11.021 